Document downloaded from:

http://hdl.handle.net/10251/159198

This paper must be cited as:

Da Trindade, LG.; Borba, KMN.; Zanchet, L.; Lima, DW.; Trench, AB.; Rey Garcia, F.; Díaz Morales, UM.... (2019). SPEEK-based proton exchange membranes modified with MOFencapsulated ionic liquid. Materials Chemistry and Physics. 236:1-11. https://doi.org/10.1016/j.matchemphys.2019.121792

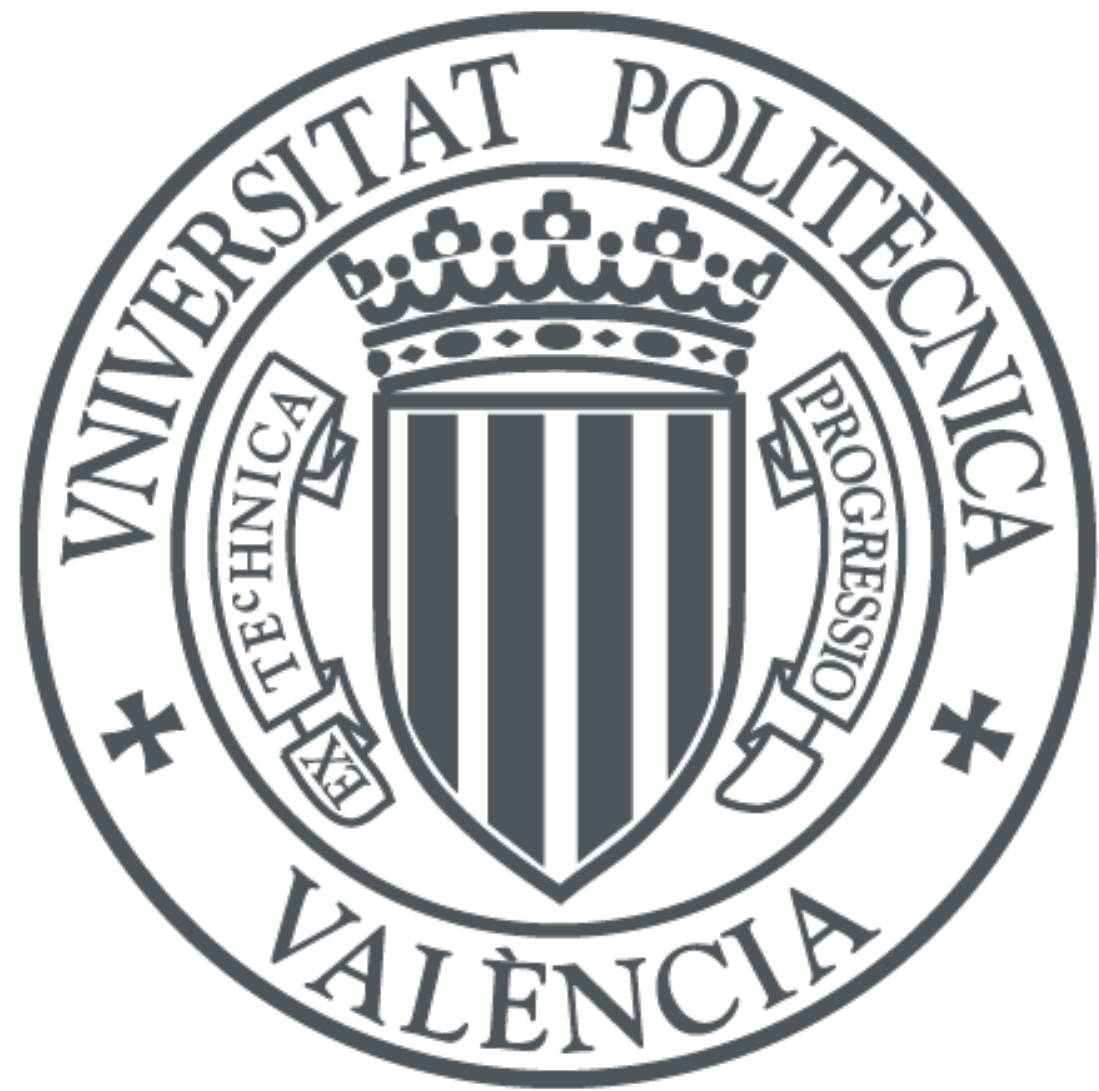

The final publication is available at

https://doi.org/10.1016/j.matchemphys.2019.121792

Copyright Elsevier

Additional Information 


\section{SPEEK-based proton exchange membranes modified with MOF- encapsulated ionic liquid}

Letícia G. da Trindade ${ }^{a}$, Katiúscia M. N. Borba ${ }^{\text {a }}$, Letícia Zanchet ${ }^{\text {a }}$, Demétrius W. Lima $^{\mathrm{a}}$, Aline B. Trench ${ }^{\mathrm{b}}$, Fernando Rey $^{\mathrm{c}}$, Urbano Diaz $^{\mathrm{c}}$, Elson Longo ${ }^{\mathrm{b}}$, Katia Bernardo-Gusmão ${ }^{\text {a }}$, Emilse M.A. Martini ${ }^{\text {a }}$

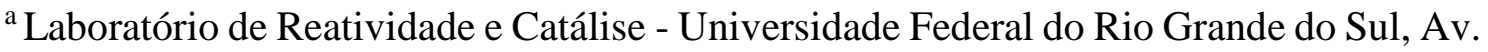
Bento Gonçalves, 9500, P.O. Box 15003, Porto Alegre 91501-970, Brazil

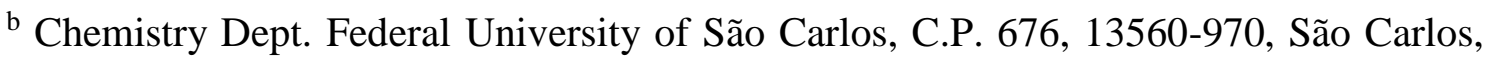
SP, Brazil

${ }^{c}$ Universidad Politécnica de Valencia, Institute of Chemical Technology (ITQ), 46022 Valencia, Spain 
Abstract: 1-butyl-3-methylimidazolium sulfate (BMI.HSO 4$)$, 1-butylimidazole sulfate $\left(\mathrm{BImH} . \mathrm{HSO}_{4}\right)$ and 3-triethylammonium hydrogen sulfate (TEA-PS.HSO 4 ) ionic liquids were encapsulated in UiO-66 ( $\mathrm{Zr}-\mathrm{MOF})$ framework. These materials were incorporated into sulfonated poly(ether ether ketone) (SPEEK) membranes in different concentrations of ionic liquid. The influence of ionic liquid concentration encapsulated in $\mathrm{Zr}-\mathrm{MOF}$ was evaluated through the morphology and thermal and chemical stability of the modified membranes. The incorporation of $7.5 \mathrm{wt} . \% \mathrm{Zr}-\mathrm{MOF}$ in SPEEK produced membranes with high proton conductivity, making this the best mass ratio for the incorporation of the ionic liquids. Contact angle and swelling analysis indicate that the presence of these ionic liquids provides stability to the membrane, preventing it from absorbing high amounts of water. Mass ratios of 2.5 and 5.0 wt.\% of encapsulated ILs in Zr-MOF were also used. Proton conductivity results show that a higher concentration of ionic liquid generates agglomerates, limiting proton mobility in the membranes. Among the three ionic liquids tested, TEA-PS.HSO 4 presents the best proton conductivity values, between 92 and $140 \mathrm{mS} \mathrm{cm}{ }^{-1}$. These results indicate a possible application in proton exchange membrane fuel cells (PEMFCs).

Keywords: metal-organic framework, ionic liquid, sulfonated poly(ether ether ketone), MOF-loaded proton exchange membrane 


\section{Introduction}

Clean energy generation with low or no $\mathrm{CO}_{2}$ emissions has been abundantly researched and developed, [1] with the promise of generating efficient and renewable energy to supply a sustainable future. Fuel cells (FCs) have stood out as a source of clean energy among numerous new technologies [2]. In this particular context, proton exchange membranes (PEMs) have been widely investigated in the last decades aiming to improve their performance in fuel cells [3]. In order for the membranes to have a better performance in FCs, they must be good proton conductors and electronically insulating at the same time. In addition, the materials used must provide thermal stability and prevent fuel crossover [4].

Nowadays, commercial membranes such as perfluorinated sulfonic acid (PFSA) membranes [5] are the most used in proton exchange membrane fuel cells (PEMFCs) and, although they have significant proton conductivity, they present disadvantages such as high production cost, high fuel permeability, high dependence on water for good performance and operating only at temperatures below $80 \mathrm{C}$ [6]. In this context, alternative membranes have been developed seeking to obtain properties such as low cost, easy synthesis, good thermal and mechanical stability and eco-friendliness [7]. The poly(ether ether ketone) (PEEK), when it passes through the sulphonation process, obtaining SPEEK, has properties comparable to those of an ideal membrane. The high degree of sulphonation of SPEEK is responsible for its high proton conductivity. However, the large amount of sulfonic groups attached to the polymer chain result in less stability in the materials in which the polymer is employed.

Studies have been carried out to overcome the issue of stability loss of SPEEK in FCs and, among the current alternatives, the use of ionic liquids has been highlighted. Ionic liquids (ILs) are conductive salts which are liquid at temperatures below $100{ }^{\circ} \mathrm{C}$ and 
ambient pressure. ILs are composed of an organic cation and an organic or inorganic anion, and are studied and applied in various electrochemical devices [8]. Its properties are advantageous for application in membranes since they confer good chemical stability to the material and high ionic conductivity [9]. In a recent work, Zhao et al. [10] investigated the use of four different ionic liquids, $[\mathrm{BMIm}]\left[\mathrm{BF}_{4}\right],[\mathrm{BMIm}] \mathrm{Cl}$, [dema][Tfo] and [EIm][Tfo], in membranes with SPEEK and mesoporous silica, and obtained satisfactory proton conductivity results, around $15 \mathrm{mS} \mathrm{cm}^{-1}$ operating at $200{ }^{\circ} \mathrm{C}$, when the ionic liquid $[\mathrm{BMIm}]\left[\mathrm{BF}_{4}\right]$ was added in the $\mathrm{SPEEK} / \mathrm{SiO}_{2}$ membrane composition.

However, IL-doped SPEEK membranes undergo IL leaching during long-term operation, which results in loss of conductivity and leading to cell failure. In order to extend the service life of the membrane and to maintain the mechanical and thermal properties acquired with the use of ionic liquids, inorganic materials such as clays and zeolites, as well as organic materials such as covalent organic (COFs) and metal-organic (MOFs) frameworks, are added to membranes with SPEEK/ILs [11].

Metal-organic frameworks (MOFs) are a new class of porous materials. Their structure is built typically from metal ions or connected through coordination bonds with organic ligands. MOFs are being investigated for countless applications and, among them, the most promising are storage and gas separation [12]. UiO-66 (UiO: University of Oslo), $\mathrm{Zr}_{6}\left(\mu_{3}-\mathrm{O}\right)_{4}\left(\mu_{3}-\mathrm{OH}\right)_{4}\left(\mathrm{O}_{2} \mathrm{C}-\mathrm{C}_{6} \mathrm{H}_{4}-\mathrm{CO}_{2}\right)_{12}$, is a highly crystalline zirconium-based MOF formed by octahedral $\mathrm{Zr}_{6} \mathrm{O}_{4}(\mathrm{OH})_{4}$, with 12-fold connections to the organic ligand 1,4-benzene-dicarboxylate (BDC). Its main advantages for use in fuel cells are related to its large surface area, stability and low electrical conductivity. Zhang et al. [13] prepared a hybrid material, SPEEK/HPW@MIL101, containing MOF MIL-101 (Cr), in the preparation of nanohybrid membranes for PEMFC applications. They demonstrated that 
this hybrid material is 7.25 times more conductive than a pristine SPEEK membrane. The effect of incorporating sulfonated MIL-101(Cr) on membrane performance was studied by $\mathrm{Li}$ et al. [14]. By incorporation of sul-MIL101(Cr), the hybrid membranes exhibited a high proton conductivity of $0.306 \mathrm{~S} \mathrm{~cm}^{-1}$ at $75^{\circ} \mathrm{C}, 100 \% \mathrm{RH}$, which is $96.2 \%$ higher than that of pristine membranes.

Here we present the encapsulation of 1-butylimidazole sulfate (BImH.HSO $)$, 1butyl-3-methylimidazolium sulfate $\left(\mathrm{BMI}^{\left.-\mathrm{HSO}_{4}\right)}\right.$ and 3-triethylammonium hydrogen sulfate (TEA-PS.HSO 4 ) ionic liquids in UiO-66 (Zr-MOF) framework. The Zr-MOF/IL material is further inserted into the SPEEK membrane synthesis to fabricate proton exchange membranes by casting method. The particles and the modified membranes are investigated by structural and morphological characterization. The pristine SPEEK and the composite membranes are compared in terms of swelling, water uptake, oxidative stability and proton conductivity.

\section{Experimental}

\subsection{Materials}

The PEEK polymer 450PF was obtained from Victrex. The sulfuric acid $\left(\mathrm{H}_{2} \mathrm{SO}_{4}\right.$ 98\%), methylene chloride $\left(\mathrm{CH}_{2} \mathrm{Cl}_{2}\right)$, N,N-dimethylformamide (DMF, 99.8\%), acetonitrile, ethyl acetate, N,N-dimethylacetamide (DMA, 99\%), triethylamine (99\%), 1chlorobutane, 1-butylimidazol (98\%), Zirconium tetrachloride $\left(\mathrm{ZrCl}_{4}\right)$ and terephthalic acid were purchased from Aldrich and were used as received. The 1.3-propane sultone and ethyl acetate were obtained from Acros Organics and Vetec, respectively.

\subsection{Ionic liquid synthesis}


3-triethylammonium propane sulfonic acid hydrogen sulfate (TEA-PS.HSO 4 ), 1butylimidazole hydrogen sulfate (BIm. $\left.\mathrm{HSO}_{4}\right)$ and 1-butyl-3-methylimidazolium hydrogen sulfate (BMI.HSO 4 ) ILs were prepared according to the literature [15-17].

In order to synthesize the TEA-PS.HSO 4 IL, the 3-triethylammonium propane sulfonic acid (TEA-PS, $56.78 \mathrm{~g}$ ) was dissolved in water (4.6 ml), and $\mathrm{H}_{2} \mathrm{SO}_{4}(14 \mathrm{ml})$ was added dropwise at $25{ }^{\circ} \mathrm{C}$. The water was removed under vacuum at $90{ }^{\circ} \mathrm{C}$ yielding a colorless viscous liquid.

The $\mathrm{BIm}_{\mathrm{HSO}} \mathrm{HS}_{4}$ was synthesized from the mixture of 1-butylimidazole $(0.2 \mathrm{~mol})$ with water $(5 \mathrm{~mL})$ with the dropwise addition of $\mathrm{H}_{2} \mathrm{SO}_{4}(0.2 \mathrm{~mol})$ in an ice bath; the reaction was stirred for $24 \mathrm{~h}$ at $25^{\circ} \mathrm{C}$. The product was dried under vacuum at $90{ }^{\circ} \mathrm{C}$ resulting in a brown liquid.

The BMI.HSO 4 IL is obtained from a cooled solution of 1-butyl-3methylimidazolium chloride (1 equivalent) in anhydrous $\mathrm{CH}_{2} \mathrm{Cl}_{2}$, in which $\mathrm{H}_{2} \mathrm{SO}_{4}$ (1 equivalent, 98\%) is dripped dropwise. This solution was refluxed during $48 \mathrm{~h}$ at $25^{\circ} \mathrm{C}$; after this time, the mixture was evaporated with a rotary evaporator for complete removal of $\mathrm{CH}_{2} \mathrm{Cl}_{2}$, resulting in a colorless liquid [18].

\subsection{Zr-MOF synthesis}

The synthesis of the UiO-66 (Zr-MOF) framework was performed by combining the reactants, terephthalic acid and zirconium chloride (IV) $\left(\mathrm{ZrCl}_{4}\right)$, with 1:1 ratio. The synthesis was performed in DMF as described in the literature $[19,20]$. In an autoclave, $1.4 \mathrm{mmol}$ of $\mathrm{ZrCl}_{4}, 1.4 \mathrm{mmol}$ of terephthalic acid and $3.6 \mathrm{mmol}$ of $\mathrm{DMF}\left(0.09 \mathrm{~mol} \mathrm{~L}^{-1}\right)$, previously solubilized, were added. The reaction was kept in a greenhouse for $24 \mathrm{~h}$ at $125^{\circ} \mathrm{C}$. The obtained crystals were filtered under reduced pressure and dried in an oven at $100{ }^{\circ} \mathrm{C}$ for $4 \mathrm{~h}$. The material was washed with methanol to remove the precursors from 
the synthesis and oven dried at $60^{\circ} \mathrm{C}$. After each washing, a XRD analysis was performed to monitor the increase in crystallinity of the material.

\subsection{Ionic liquid encapsulation}

The method used for ionic liquid encapsulation in the Zr-MOF was wet impregnation. This method consists of: (i) dissolving the ionic liquid in excess of ethanol; (ii) adding the $\mathrm{Zr}-\mathrm{MOF}$ to this mixture and stirring for $4 \mathrm{~h}$ at room temperature; and (iii) after obtaining a homogenous solution, oven-evacuating the solvent at $80{ }^{\circ} \mathrm{C}$ for $6 \mathrm{~h}$, and the $\mathrm{Zr}-\mathrm{MOF} / \mathrm{IL}$ composite is obtained as a powder [21].

\subsection{SPEEK preparation}

The SPEEK membrane was prepared according to the literature [22]. The poly (ether ether ketone) (10g) was dissolved in $\mathrm{H}_{2} \mathrm{SO}_{4}(250 \mathrm{ml}, 98 \%)$ under inert atmosphere; the solution was stirred for $20 \mathrm{~h}$ at $25^{\circ} \mathrm{C}$. Afterwards, the polymer solution was precipitated in excess of deionized water and ice under continuous stirring, and the polymer was washed to $\mathrm{pH} 5$. The SPEEK polymer was dried under vacuum at $60{ }^{\circ} \mathrm{C}$ until its color turned yellow. The degree of sulfonation obtained was $66 \%$ and was calculated by ${ }^{1} \mathrm{H}-\mathrm{NMR}[23]$.

\subsection{Membranes preparation}

Proportional amounts of SPEEK and $\mathrm{Zr}-\mathrm{MOF}$ were mixed in DMA at $80^{\circ} \mathrm{C}$ under constant stirring for $8 \mathrm{~h}$. The homogeneous mixture was poured onto a petri dish and dried in a vacuum oven at $80{ }^{\circ} \mathrm{C}$ for $24 \mathrm{~h}$. The denominations given for the prepared samples and their respective compositions are shown in Table 1. 
Table 1. Composition and sample designation of the composite membranes.

\begin{tabular}{ccc}
\hline Sample & SPEEK (g) & $\begin{array}{c}\text { Zr-MOF } \\
(\mathbf{w t} \%)\end{array}$ \\
\hline S0 & 0.50 & - \\
SMOF2.5 & 0.50 & 2.5 \\
SMOF5 & 0.50 & 5.0 \\
SMOF7.5 & 0.50 & 7.5 \\
SMOF10 & 0.50 & 10.0 \\
\hline
\end{tabular}

After evaluating the structure of these composite membranes SPEEK/Zr-MOF by ATR-FTIR and TG analysis and evaluating their proton conductivity in conditions of contoured relative humidity at 25 and $80{ }^{\circ} \mathrm{C}$, the membrane with 7.5 wt. $\%$ of $\mathrm{Zr}$-MOF was chosen for addition of ionic liquid, because it had the highest proton conductivity among the samples studied.

The ionic liquids employed in the $\mathrm{Zr}-\mathrm{MOF}$ were TEA-PS.HSO $4, \mathrm{BIm}^{\mathrm{HSO}} \mathrm{HS}_{4}$ and BMI.HSO 4 . These composite membranes were prepared using 2.5 or $5 \mathrm{wt} . \%$ of IL encapsulated in Zr-MOF. The chemical structure of SPEEK and the ionic liquids used are shown in Figure 1, and the denominations given for the composite membranes and their respective compositions are shown in Table 2.

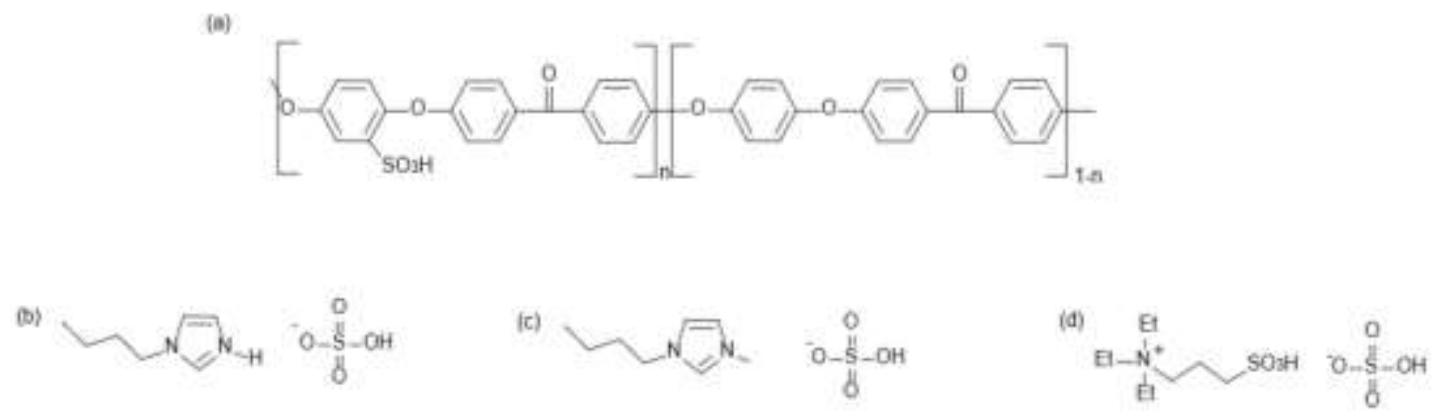

Figure 1. Chemical structures of SPEEK (a), BIm.HSO 4 (b), $\mathrm{BMI}_{\mathrm{HSO}}$ (c) and TEA$\mathrm{PS} . H S O_{4}$ (d). 
Table 2. Sample designation and composition of the membranes.

\begin{tabular}{ccccc}
\hline Sample & SPEEK (g) & $\begin{array}{c}\text { Zr-MOF } \\
(\mathbf{w t} \%)\end{array}$ & $\begin{array}{c}\text { Ionic liquid } \\
\text { S0 }\end{array}$ & $\begin{array}{c}\text { Ionic liquid } \\
(\mathbf{w t . \%})\end{array}$ \\
\hline SMOF/TEA2.5 & 0.40 & - & - & - \\
SMOF/TEA5 & 0.40 & 7.5 & TEA-PS.HSO $_{4}$ & 5.0 \\
SMOF/BH2.5 & 0.40 & 7.5 & BImH.HSO $_{4}$ & 2.5 \\
SMOF/BH5 & 0.40 & 7.5 & BImH.HSO $_{4}$ & 5.0 \\
SMOF/BM2.5 & 0.40 & 7.5 & BMI.HSO $_{4}$ & 2.5 \\
SMOF/BM5 & 0.40 & 7.5 & BMI.HSO $_{4}$ & 5.0 \\
\hline
\end{tabular}

\subsection{Characterizations}

The Zr-MOF and Zr-MOF/IL powders were investigated using X-ray diffraction (XRD) and $\mathrm{N}_{2}$ adsorption-desorption isotherm measurements. The XRD analyses were performed using a Rigaku detector with $\mathrm{Cu} K \alpha$ radiation $(\lambda=0.15406 \mathrm{~nm})$ in the $2 \theta$ range of 2 to $80^{\circ}$ using $0.05^{\circ} \min ^{-1}$ steps. The specific surface area was determined using the Brunauer-Emmett-Teller (BET) method at $-196{ }^{\circ} \mathrm{C}$, at a partial pressure $\mathrm{P} / \mathrm{P}_{0}<1$. The pore size distribution was calculated using the $\mathrm{N}_{2}$ adsorption-desorption isotherms and the classic theoretical model of Barrett, Joyner, and Halenda (BJH).

The attenuated total reflectance Fourier transform infrared spectroscopy (ATRFTIR) spectra of SPEEK/Zr-MOF and SPEEK/Zr-MOF/IL membranes were measured with Bruker Alpha-P spectrometer in the range $4000-500 \mathrm{~cm}^{-1}$. The thermal stability of the samples was determined by Thermal Gravimetric Analysis (TGA), using a TA Instruments Q-50 apparatus in the temperature range from 20 to $700{ }^{\circ} \mathrm{C}$ at $20{ }^{\circ} \mathrm{C} \mathrm{min}{ }^{-1}$ under $\mathrm{N}_{2}$ atmosphere. 
The crystal structures of the pure SPEEK and SPEEK/Zr-MOF-IL composite membranes were ascertained by X-ray diffraction (XRD) analysis, using a Rigaku X-ray diffractometer with a $\mathrm{Cu}-\mathrm{K} \alpha$ radiation source, over the range $2^{\circ} \leq 2 \theta \leq 80^{\circ}$.

The morphology of Zr-MOF and Zr-MOF/IL particles and the cross-section of the membranes were observed using field-emission gun-scanning electron microscopy (FEGSEM).

The topography images were analyzed by a Bruker Controur GT-K profilometer, with Vision 64 software and, for information on the hydrophilic or hydrophobic membranes surface, the contact angle was measured using a Kruss DSA 30 at $25^{\circ} \mathrm{C}$.

The water uptake and the leaching measurements of the samples were determined by mass difference. The membranes were dried at $80{ }^{\circ} \mathrm{C}$ under vacuum for $24 \mathrm{~h}$ and immersed in deionized water at $80{ }^{\circ} \mathrm{C}$ for $24 \mathrm{~h}$. The water uptake was calculated by the formula

$$
\text { Water uptake }(\%)=\frac{W_{\mathrm{w}}-W_{\mathrm{d}}}{W_{\mathrm{d}}} \times 100 \%
$$

were $W_{\mathrm{w}}$ is the mass of the wet membrane and $W_{\mathrm{d}}$ is the mass of the dry membrane with absorbent paper.

The leaching out of Zr-MOF/IL composite was calculated using the formula

$$
\text { Leaching }(\%)=\frac{W_{\mathrm{f}}-W_{\mathrm{i}}}{W_{\mathrm{f}}} \times 100 \%
$$

where $W_{\mathrm{i}}$ is initial mass of dry sample and $W_{\mathrm{f}}$ is the mass after immersion in deionized water and, dried in a vacuum oven at $80{ }^{\circ} \mathrm{C}$ for $24 \mathrm{~h}$.

The oxidative stability of the samples was investigated by soaking $1.0 \times 2.0 \mathrm{~cm}$ membrane pieces in Fenton's reagent $\left(4 \mathrm{ppm} \mathrm{Fe}{ }^{+2}\right.$ in $\left.3 \% \mathrm{H}_{2} \mathrm{O}_{2}\right)$ at $80{ }^{\circ} \mathrm{C}$. For this test, the membranes were weighted $\left(W_{1}\right)$, then placed in $20 \mathrm{~mL}$ of Fenton solution and kept at 80 ${ }^{\circ} \mathrm{C}$ for $24 \mathrm{~h}$. Subsequently, the sample was collected by filtering, cleaned with deionized water, dried in a vacuum oven at $80^{\circ} \mathrm{C}$ for $24 \mathrm{~h}$, and then weighed $\left(W_{2}\right)$. The oxidative stability was calculated using the formula bellow: 


$$
\text { Oxidative stability }(\%)=\frac{W_{1}-W_{2}}{W_{1}} \times 100 \%
$$

The proton conductivity of the samples was determined by electrochemical impedance spectroscopy (EIS) method using an Autolab PGSTAT30 potentiostat from $10 \mathrm{~Hz}$ to $100 \mathrm{kHz}, 0.01 \mathrm{~V} \mathrm{AC}$ perturbation and open-circuit potential. The samples were cut into pieces of $20 \mathrm{~mm} \times 15 \mathrm{~mm}$, clamped by the edges between stainless steel electrodes and placed in a cel with controlle temperature and relative humidity (RH). The conductivity was measured at 25 and at $80{ }^{\circ} \mathrm{C}$ after the sample was equilibrated at 100 and $60 \% \mathrm{RH}$, respectively. The proton conductivitie $(\sigma)$ in the longitudinal direction was calculated by the following formula [24]:

$$
\sigma=\frac{L}{R d W}
$$

where $L$ is the distance between the electrodes, $d$ is the thickness and $W$ the width of the membrane, and $R$ is the resistance value calculated from EIS spectra.

\section{Results and Discussion}

Figure 2 (a) shows the ATR-FTIR spectra of S0, SMOF2.5, SMOF7.5 and SMOF10 samples. The pure SPEEK membrane (S0) has a strong absorption at $3440 \mathrm{~cm}^{-}$

${ }^{1}$ that can be related to the $\mathrm{O}-\mathrm{H}$ from the $\mathrm{SO}_{3} \mathrm{H}$ group. The peaks at 1491 and $1478 \mathrm{~cm}^{-1}$ are attributed to the aromatic C-C band. The peaks at 1224 and $1083 \mathrm{~cm}^{-1}$ are related to symmetric and asymmetric stretching vibrations of the $\mathrm{SO}_{3} \mathrm{H}$ group in the SPEEK polymer [25]. For SMOF2.5, SMOF7.5 and SMOF10 similar spectra can be observed. These spectra have the same characteristic peaks of SPEEK, although it can be observed that the intensity of the peaks decreases with increasing amount of $\mathrm{Zr}$-MOF in the membrane. The peaks at 1587 and $1394 \mathrm{~cm}^{-1}$ are attributed to the $\mathrm{O}-\mathrm{C}-\mathrm{O}$ asymmetric and symmetric stretching in the terephtalic acid ligand, and the peak at $554 \mathrm{~cm}^{-1}$ can be 
attributed to the $\mathrm{Zr}-(\mathrm{OC})$ asymmetric stretch $[26,27]$. These data confirm the insertion of Zr-MOF in the polymer matrix.
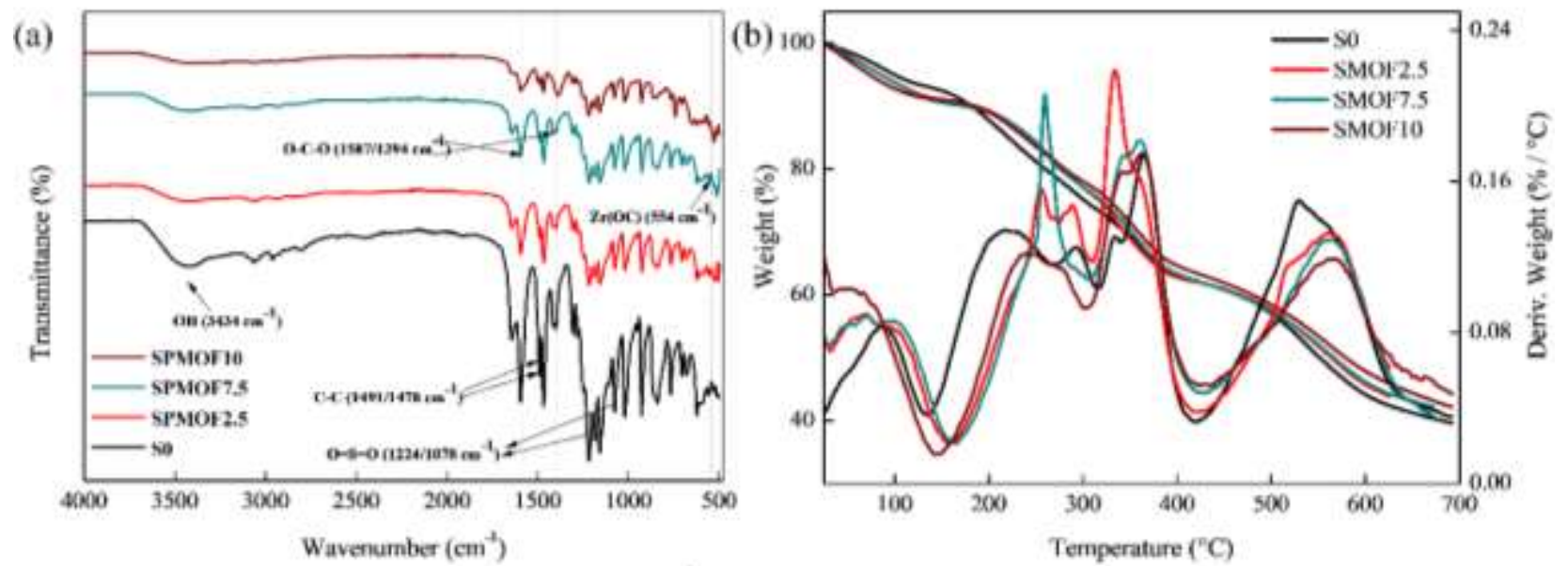

Figure 2. ATR-FTIR spectra (a) and TG curves (b) for S0, SMOF2.5, SMOF7.5 and SMOF10 samples.

The thermal properties of the pure and composite membranes were evaluated by TG analysis. The TG curves under $\mathrm{N}_{2}$ atmosphere for $\mathrm{S} 0$ and SPEEK with 2.5, 7.5 and 10 wt.\% of Zr-MOF are shown in figure 2 (b). For the pristine SPEEK membrane (S0), we can observe three distinct steps of mass loss. The first, between 87 and $220{ }^{\circ} \mathrm{C}$, is attributed to evaporation of water molecules absorbed in the sample; the second mass loss step, between 220 and $365^{\circ} \mathrm{C}$, is due to decomposition of functional sulfonic acid groups; and the last step, at approximately $530{ }^{\circ} \mathrm{C}$, may be attributed to the degradation of the main chain of the SPEEK membrane [28]. Membranes containing Zr-MOF exhibit the same behavior as pure SPEEK. However, it can be seen that the second stage of mass loss starts at slightly higher temperature: approximately $260{ }^{\circ} \mathrm{C}$ for the samples with 2.5 and 7.5 wt. $\%$ of $\mathrm{Zr}-\mathrm{MOF}$ and $240{ }^{\circ} \mathrm{C}$ for the sample with $10 \mathrm{wt} . \%$ of this material. Moreover, although the last degradation stage starts at the same temperature (approximately $560{ }^{\circ} \mathrm{C}$ ), it is observed that, with the addition of $\mathrm{Zr}-\mathrm{MOF}$, the membranes present a lower mass 
loss at the end of the stage. This result indicates that the addition of $\mathrm{Zr}$-MOF to the polymer matrix confers thermal stability to the composite membrane. This additional thermal stability imparted to the polymer may be due to the hydrogen bonding interactions in the SPEEK/Zr-MOF membranes.

The proton conductivity of the S0 and composites membranes with different $\mathrm{Zr}$ MOF amounts at $25^{\circ} \mathrm{C} / 100 \% \mathrm{RH}$ and $80{ }^{\circ} \mathrm{C} / 60 \% \mathrm{RH}$ is presented in Table 3 . The data reveals that the incorporation of $\mathrm{Zr}-\mathrm{MOF}$ in the polymer facilitates proton conduction when the material content is up to $7.5 \mathrm{wt} \%$, whereas the proton conductivity of the composite membrane is reduced when $\mathrm{Zr}-\mathrm{MOF}$ content is $10 \mathrm{wt} \%$. This reduction in protonic conductivity can be attributed to the fact that this amount of $\mathrm{Zr}-\mathrm{MOF}$ (10 wt.\%) exceeds the maximum pore size of the polymer, thus making it difficult to diffuse and to occupy the water swelled pores in the polymer matrix [29]. The proton conductivity of all membrane samples increases with temperature and $\mathrm{Zr}-\mathrm{MOF}$ content. The pristine membrane (S0) displays a proton conductivity of $77 \mathrm{mS} \mathrm{cm}-1$ at $25^{\circ} \mathrm{C}$ and $126 \mathrm{mS} \mathrm{cm}{ }^{-1}$ at $80^{\circ} \mathrm{C}$. The SPEEK/MOF composite membranes show enhanced proton conductivity in both temperatures, reaching 141, 146, 172 and $129 \mathrm{mS} \mathrm{cm}^{-1}$ for SMOF2.5, SMOF5, SMOF7.5 and SMOF10, respectively, at $80^{\circ} \mathrm{C}$. This increase in conductivity with addition of Zr-MOF may report that this material has unsaturated metal sites which can provide a significant amount of $\mathrm{OH}$ groups by hydrolysis. By hydrogen bonds, these $\mathrm{OH}$ groups can facilitate proton conduction by the Grotthuss mechanism $[14,30]$. The increase of the $\mathrm{Zr}-\mathrm{MOF}$ concentration in the polymer matrix increased the number of metal sites, which facilitates the construction of the hydrogen bonding networks.

Table 3. Proton conductivity $(\sigma)$ and relative humidity $(\mathrm{RH})$ of SPEEK/MOF composite membranes with different amounts of $\mathrm{Zr}-\mathrm{MOF}$ at $25^{\circ} \mathrm{C}$ and $80^{\circ} \mathrm{C}$. 


\begin{tabular}{ccc}
\hline Sample & \multicolumn{2}{c}{$\left(\mathbf{m S ~ c m}^{-\mathbf{1}}\right)$} \\
& $\mathbf{2 5}^{\mathbf{0}} \mathbf{C}(\mathbf{1 0 0 \%} \mathbf{R H})$ & $\mathbf{8 0}^{\mathbf{0}} \mathbf{C}(\mathbf{6 0 \%} \mathbf{R H})$ \\
S0 & 77 & 126 \\
SMOF2.5 & 84 & 141 \\
SMOF5 & 96 & 146 \\
SMOF10 & 104 & 172 \\
& 85 & 129 \\
\hline
\end{tabular}

The results for SPEEK/MOF membranes with concentrations 2.5, 5, 7.5 and 10 wt.\% Zr-MOF show that an increase in Zr-MOF concentration causes an improvement in membrane conductivity, with a limit value reached when $7.5 \mathrm{wt} . \% \mathrm{Zr}-\mathrm{MOF}$ in the polymer was used. The conductivity of the SMOF10 sample undergoes a drastic decrease in its value when compared to the SMOF7.5 membrane. Through thermal analysis it is evident that the increase in $\mathrm{Zr}$-MOF concentration from $7.5 \mathrm{wt} . \%$ to $10 \mathrm{wt} . \%$ is also accompanied by loss of thermal stability in the material, since the SMOF10 sample decomposes at a lower temperature when compared to the other samples. Considering these results, the amount of Zr-MOF to be placed on the SPEEK membrane was set at 7.5 wt.\%.

The Zr-MOF and Zr-MOF/IL powders were characterized by XRD, BET and FEG-SEM analysis. The XRD analysis for Zr-MOF, Zr-MOF/BH5, Zr-MOF/BM5 and Zr-MOF/TEA5 particles are shown in Figure 3. 


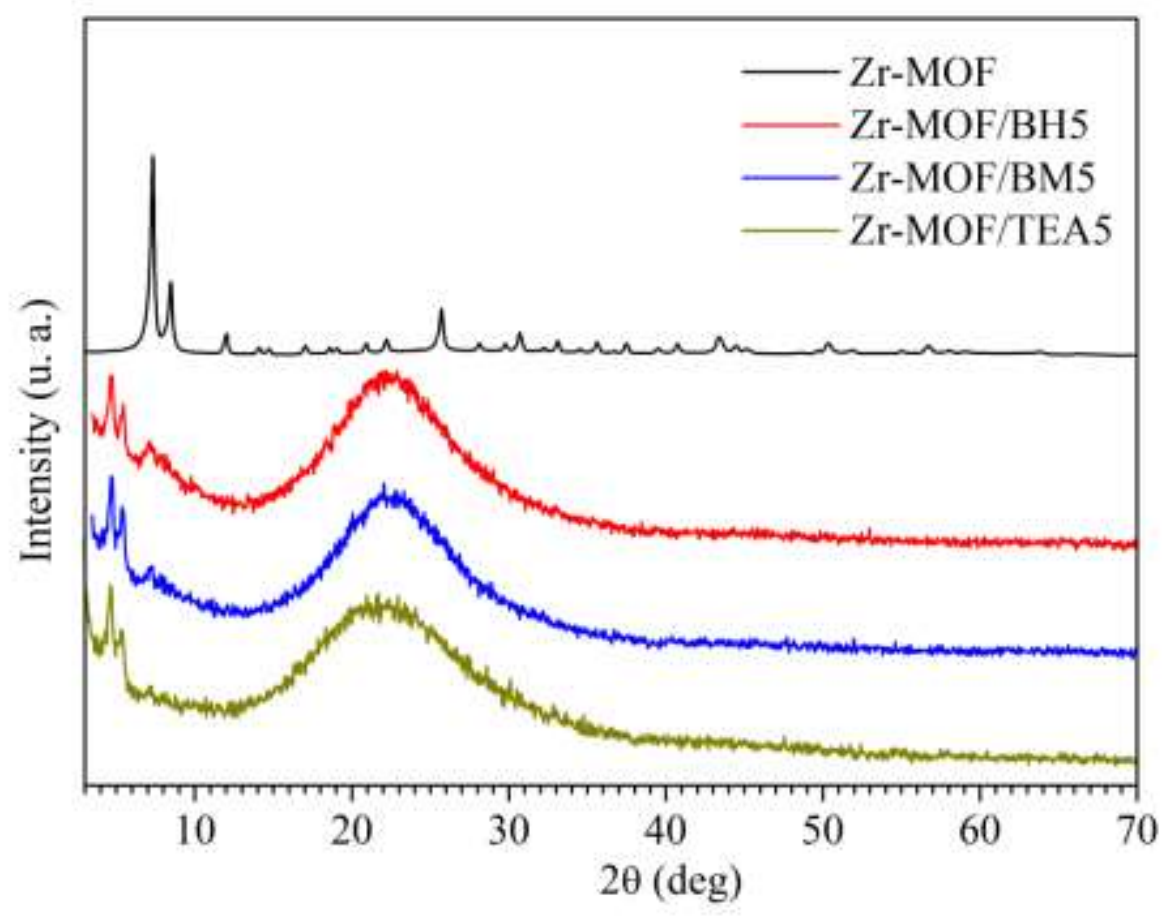

Figure 3. XRD analysis of Zr-MOF, Zr-MOF/BH5, Zr-MOF/BM5 and Zr-MOF/TEA5.

The crystalline structure of the UiO-66 MOF can be confirmed by XRD analysis. The pure MOF diffractogram shows the crystallographic planes (111), (002), (113), (004), (115), (224), (046), and (137) relating to the $2 \theta$ peaks of $7.2^{\circ}, 8.1^{\circ}, 11.3^{\circ}, 13.8^{\circ}$, $16.7^{\circ}, 21.9^{\circ}, 25.3^{\circ}, 30.6^{\circ}$ and $32.8^{\circ}$ [31]. It is possible to observe a large amorphous halo around $22^{\circ}$ for the MOF/IL samples, probably due to the presence of ionic liquid. Moreover, the characteristic peaks of the MOF associated to the planes (111), (002) and (113) are shifted to values less than $2 \theta$, attesting to the increase in interplanar distances in relation to $\mathrm{Zr}-\mathrm{MOF}$ without ionic liquid, which suggests that the IL is occupying the pores of the MOF structure. In addition, it is possible to observe a decrease in the intensity of the peak around $7.2^{\circ}$ with the increase of the molar mass of IL, suggesting that a larger molar mass of the ionic liquid can hinder the crystallization of the $\mathrm{Zr}-\mathrm{MOF}$. 
The $\mathrm{N}_{2}$ adsorption/desorption curves for analysis by the BET method) for pure $\mathrm{Zr}$ MOF, Zr-MOF/BH5, Zr-MOF/BM5 and Zr-MOF/TEA5 are shown in Figure 4.

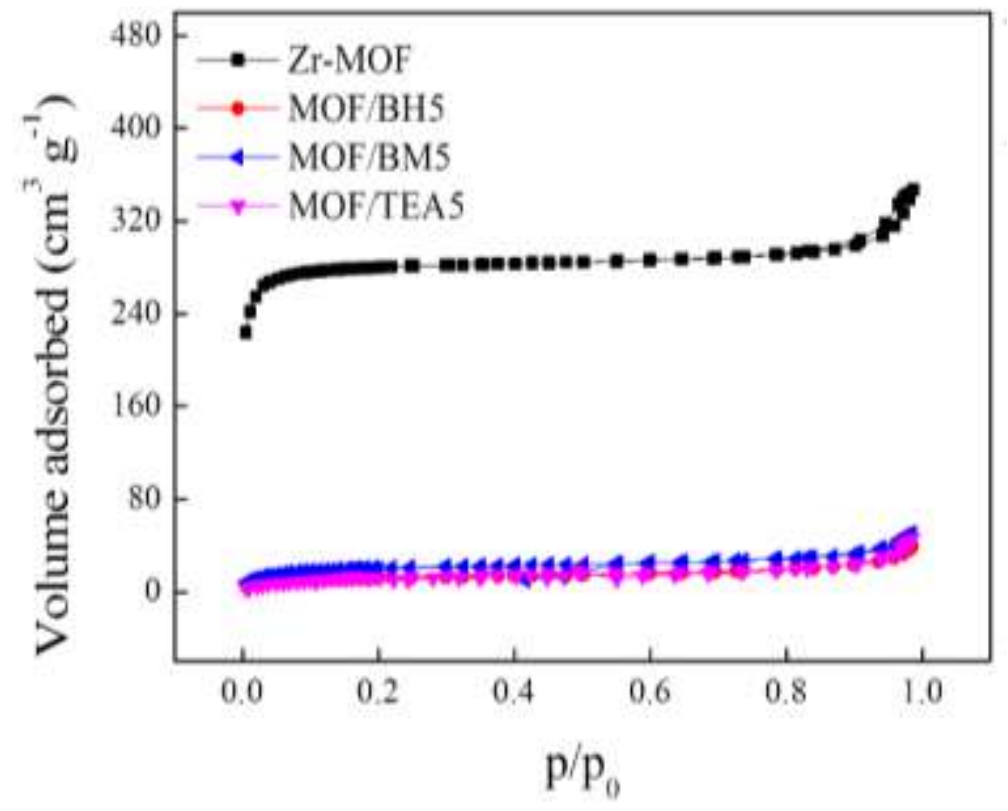

Figure 4. $\mathrm{N}_{2}$ sorption isotherms, BET surface area (BET area) and pore volume for $\mathrm{Zr}$ MOF, MOF/BM5, MOF/BH5 and MOF/TEA5 samples.

It can be observed in the diagram that the volume of adsorbed gas is much higher for pure $\mathrm{Zr}-\mathrm{MOF}$; this is due to the absence of ionic liquid in the pores of the material. The specific area was determined by the BET method; the following values were obtained: $987 \mathrm{~m}^{2} / \mathrm{g}$ (Zr-MOF), $72 \mathrm{~m}^{2} / \mathrm{g}$ (MOF/BM5), $49 \mathrm{~m}^{2} / \mathrm{g}$ (MOF/BH5) and $42 \mathrm{~m}^{2} / \mathrm{g}$ (MOF/TEA5). The pore volume was calculated by the BJH method; the following values were obtained: $\quad 0.52 \mathrm{~cm}^{3} / \mathrm{g} \quad(\mathrm{Zr}-\mathrm{MOF}), \quad 0.074 \mathrm{~cm}^{3} / \mathrm{g} \quad(\mathrm{MOF} / \mathrm{BM} 5), \quad 0.063 \mathrm{~cm}^{3} / \mathrm{g}$ (MOF/BH5) e $0.056 \mathrm{~cm}^{3} / \mathrm{g}(\mathrm{MOF} / \mathrm{TEA} 5)$. The decrease in specific area and pore volume values confirm that the ionic liquid fills the pores of the material. The MOF/TEA system presents the smallest specific area and the smaller volume of $\mathrm{N}_{2}$ gas adsorbed in the $\mathrm{Zr}$ MOF cavities, which confirms the results obtained by the XRD analysis and shows that the molar mass of ionic liquid is correlated with variation of the pores size. 
The FEG-SEM images for pure Zr-MOF and MOF/IL particles are shown in Figure 5.
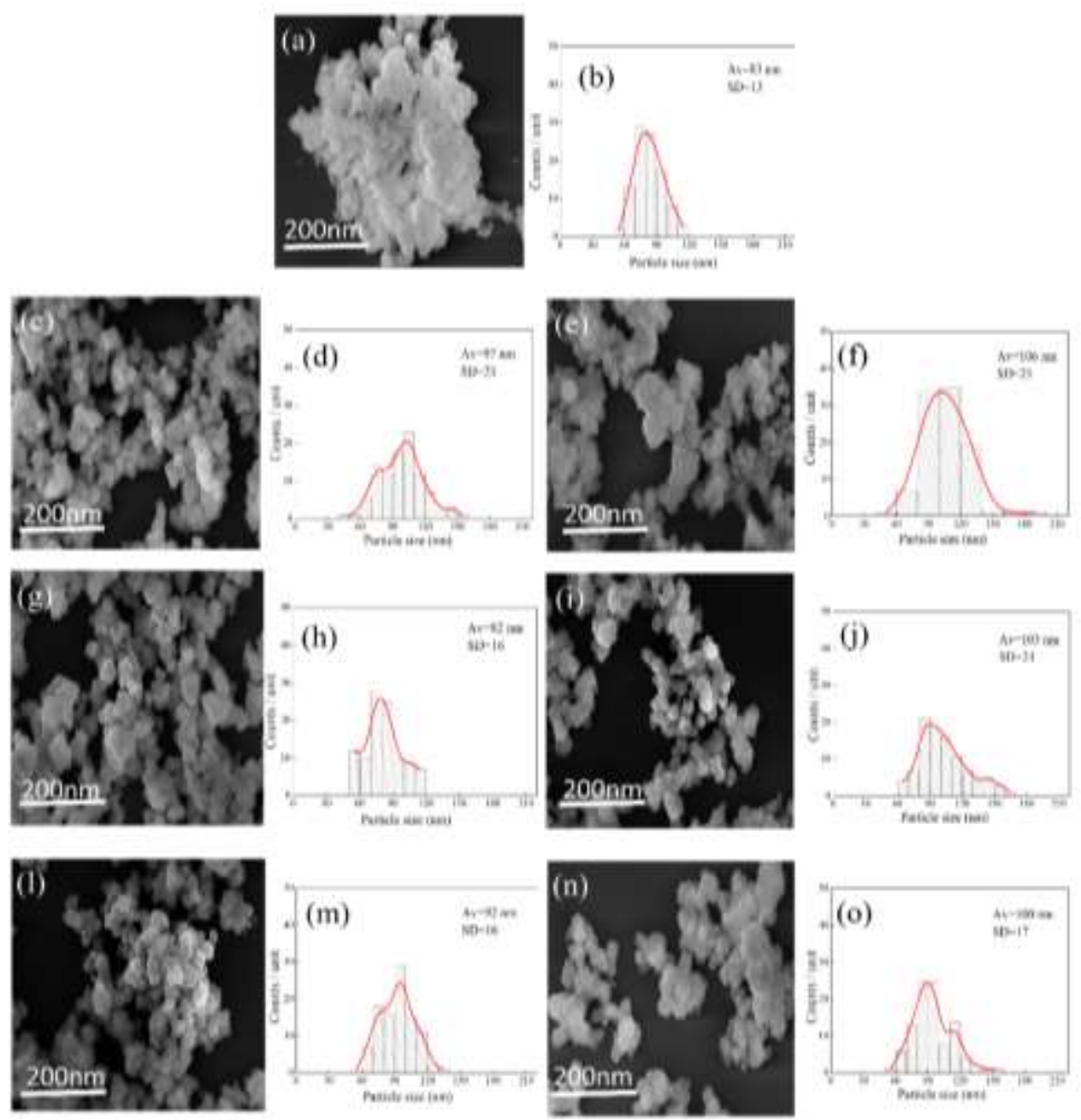

Figure 5. FEG-SEM images and size distributions of Zr-MOF (a-b), MOF/BH2.5 (c-d), MOF/BH5 (e-f), MOF/BM2.5 (g-h), MOF/BM5 (i-j), MOF/TEA2.5 (l-m) and MOF/TEA5 (n-o) particles.

It can be observed in Figure 5 that the addition of ionic liquid in the $\mathrm{Zr}-\mathrm{MOF}$ causes a decrease in the degree of agglomeration of the particles, and the presence of cubic structures is observed as the concentration of ionic liquid increases. This behavior can be attributed to an increase of the acidity of the medium with the addition of ILs. The $\mathrm{pH}$ of the ionic liquids is 2.2, 3.8 and 1.3 for $\mathrm{BIm}_{\mathrm{HSO}}, \mathrm{BMI}_{4} \mathrm{HSO}_{4}$ and TEAPS.HSO 4 , respectively. As the acidity of the medium acidity increases, more cube-shaped crystals 
are observed, Fig.5 (c, g and 1), however these cubes present in varying sizes and gradually become larger with increasing IL concentration, as it can be seen in Figure 5 (f, $\mathrm{j}$ and $\mathrm{o}$ ). This behavior indicates that the ionic liquid is acting as a structure modulator, and the more acid the IL, more cubic structures are observed. However, the mean particle size does not change significantly when the amount of IL added is $2.5 \mathrm{wt}$. $\%$. When the amount of IL is doubled (5 wt.\%) an increase in particle size is observed, however the mean size is practically the same for the three ILs.

After the characterization of $\mathrm{Zr}-\mathrm{MOF} / \mathrm{IL}$ particles, SPEEK modified membranes were manufactured with this material by the casting method. These composite membranes were morphologically and structurally characterized and compared to the SMOF7.5 membrane in order to evaluate the effects of the ionic liquids encapsulated in the Zr-MOF particles.

The ATR-FTIR spectra for SMOF/TEA2.5, SMOF/TEA5, SMOF/BH2.5, SMOF/BH5, SMOF/BM2.5 and SMOF/BM5 modified membranes are shown in Figure 6.
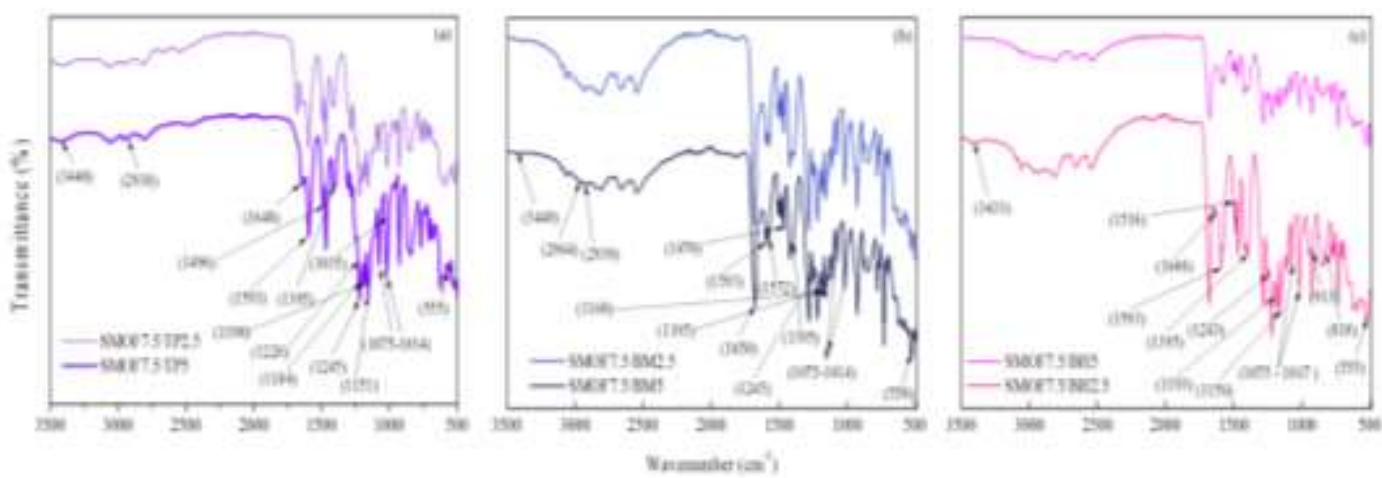

Figure 6. ATR-FTIR spectra for SMOF/TEA2.5, SMOF/TEA5, SMOF/BH2.5, SMOF/BH5, SMOF/BM2.5 and SMOF/BM5.

In Figure $6(\mathrm{a}-\mathrm{c})$ it is shown that, regardless of the ionic liquid added, composite membranes retain the same characteristic peaks as pristine SPEEK and Zr-MOF. The 
peaks at 1245,1075 and $1014 \mathrm{~cm}^{-1}$ are attributed to the sulfonic acid group, referring to symmetrical and asymmetric $\mathrm{O}=\mathrm{S}=\mathrm{O}$ stretching vibrations [32]. The presence of the peak at $3440 \mathrm{~cm}^{-1}$ is another evidence of the presence of the $-\mathrm{SO}_{3} \mathrm{H}$ group, since this is attributed to the $\mathrm{O}-\mathrm{H}$ vibration of the sulfonic acid group [33]. The peak at $1648 \mathrm{~cm}^{-1}$ is attributed to the backbone $\mathrm{C}=\mathrm{O}$ [33]. The evidence that $\mathrm{Zr}-\mathrm{MOF}$ has been inserted into the membrane is the presence of the peaks at 1593 and $1395 \mathrm{~cm}^{-1}$ that are associated respectively with the asymmetric and symmetric oscillations of the $\mathrm{O}=\mathrm{C}=\mathrm{O}$ of the carboxylate group of terephthalic acid. In addition, the peak at approximately $555 \mathrm{~cm}^{-1}$ is attributed to the $\mathrm{Zr}$-(OC) asymmetric stretch [34]. When the ionic liquid encapsulated in the $\mathrm{Zr-MOF}$ is TEAPS.HSO 4 , the spectrum in Figure 6(a) displays peaks at 2938 and $1496 \mathrm{~cm}^{-1}$ which are attributed to the axial deformation and the angular deformation of the $\mathrm{C}-\mathrm{H}$ bond, respectively. The peaks at 1228,1184 and $1035 \mathrm{~cm}^{-1}$ refers to asymmetric axial deformation of the $\mathrm{S}=\mathrm{O}$ bond and axial deformation of the S-O bond of TEA-PS, respectively [35]. Moreover, the peaks at 1193 and $1151 \mathrm{~cm}^{-1}$ reports to antisymmetric $\mathrm{SO}_{2}$ stretching and $\mathrm{SOH}$ bending modes, respectively [36]. When the $\mathrm{BMI} . \mathrm{HSO}_{4}$ was encapsulated, the peaks at 2964 and $2939 \mathrm{~cm}^{-1}$ in Figure 6 (b) are assigned to $\mathrm{C}-\mathrm{H}, \mathrm{CH}_{2}$ and $\mathrm{CH}_{3}$ stretching peak on the lateral chain of the imidazole ring [37]. The peaks in 1574 and $1467 \mathrm{~cm}^{-1}$ refers to skeletal vibration peaks of imidazole ring, and the peaks at approximately 1195 and $1160 \mathrm{~cm}^{-1}$ are attributed to antisymmetric $\mathrm{SO}_{2}$ stretching and $\mathrm{SOH}$ bending modes, respectively [36]. When the encapsulated ionic liquid is BImH.HSO 4 the peak at $1516 \mathrm{~cm}^{-1}$ in Figure 6 (c) is attributed to in-plane stretching of the $\mathrm{CH}_{2}(\mathrm{~N}) \mathrm{CN}$ ring. The peaks at $913 \mathrm{~cm}^{-1}$ and $818 \mathrm{~cm}^{-1}$ are assigned to $\mathrm{N}-\mathrm{H}$ out-plane bending and $\mathrm{NC}(\mathrm{H}) \mathrm{NCH}$ bending vibrations, respectively [38]. Finally, the peaks at 1193 and $1156 \mathrm{~cm}^{-1}$ refers to antisymmetric $\mathrm{SO}_{2}$ stretching and $\mathrm{SOH}$ bending modes, respectively [36]. 
The XRD patterns of the pure Zr-MOF, S0, SMOF7.5, SMOF/BH5, SMOF/BM5 and SMOF/TEA5 samples are shown in Figure 7.

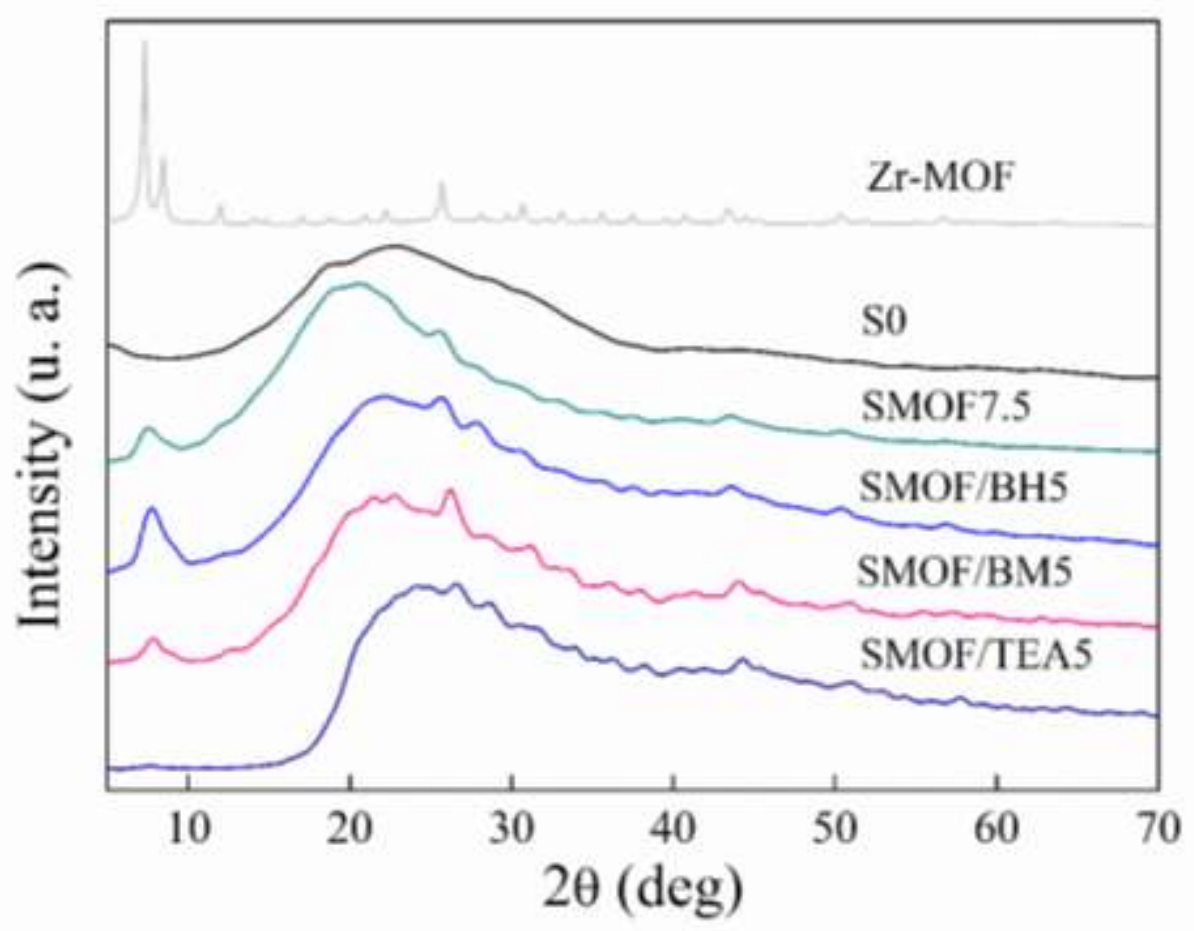

Figure 7. XRD for Zr-MOF, S0, SMOF7.5, SMOF/BH5, SMOF/BM5 and SMOF/TEA5 samples.

The influence of the ionic liquids in the formation of $\mathrm{Zr}$-MOF inside the pores of the membrane is shown in the diffractograms of these composite membranes in Figure 7. The diffraction pattern of Zr-MOF exhibit characteristic peaks of crystalline materials while the diffractogram of the SPEEK membrane (S0) presents a wide and flatted halo characteristic of a completely amorphous material [39]. The diffraction patterns of all composite membranes with $\mathrm{Zr}-\mathrm{MOF}$ show the characteristic halo of the polymer membrane but also some flattened peaks that can be related to the formation of $\mathrm{Zr}-\mathrm{MOF}$ in this membrane. It is interesting to observe the peak around $7.4^{\circ}(2 \theta)$ in the diffraction patterns of composite membranes with the addition of ionic liquid. This peak is related to the overlap of MOF peaks (111) and (200), and can be considered a MOF crystallinity 
parameter in the membranes [40]. This peak is relatively intense in the composite

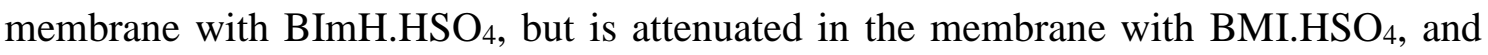
practically non-existent in the membrane with TEA-PS.HSO 4 . This fact suggests a decrease in particle size, or in crystallinity, from the BImH.HSO 4 system $(\mathrm{SMOF} / 5 \mathrm{BH})$ to the BMI.HSO 4 system (SMOF/5BM). The Zr-MOF on the membrane with TEA$\mathrm{PS} . H S O_{4}(\mathrm{SMOF} / 5 \mathrm{TEA})$ is practically amorphous. Probably, the molar mass or the size of the ionic liquid interferes with the formation of the $\mathrm{Zr}-\mathrm{MOF}$ particle in the membrane pores. The BImH.HSO 4 ionic liquid molecule occupies little space inside the $\mathrm{Zr}-\mathrm{MOF}$ pore and allows the development of more crystalline and probably larger $\mathrm{Zr}-\mathrm{MOF}$ particles. The molecule of $\mathrm{BMI}^{-\mathrm{HSO}_{4}}$ is larger than that $\mathrm{BImH}_{\mathrm{HSO}}$ and slightly disturbs the formation of these $\mathrm{Zr}-\mathrm{MOF}$ nanoparticles. However, TEA-PS. $\mathrm{HSO}_{4}$ has a very large molecule, which occupies much of the membrane pore, and does not allow the full formation of the Zr-MOF nanoparticles, resulting in a poorly crystalline material.

In order to determine whether the encapsulation of ionic liquids into the $\mathrm{Zr}-\mathrm{MOF}$ maintains the thermal stability of pure $\mathrm{Zr}-\mathrm{MOF}$, TG analysis was performed. The analysis of SMOF7.5, SMOF/TEA5, SMOF/BH5 and SMOF/BM5 membranes is shown in Figure S1. It can be seen that the impregnation of Zr-MOF by TEA-PS.HSO $4, \mathrm{BIm}_{4} \mathrm{HSO}_{4}$ or

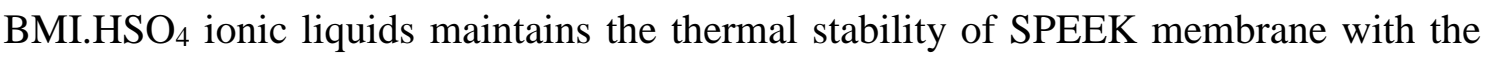
addition of $7.5 \mathrm{wt} \% \mathrm{Zr}-\mathrm{MOF}$. The SPEEK/MOF-IL composite membranes have the same behavior as the SPPEK/MOF membranes, that is, with the same three stages of degradation. The first stage is the loss of water or residual solvent. The second stage, which refers to degradation of the sulfonic acid group in the range of 240 to $402^{\circ} \mathrm{C}$, shows more significant difference between the composite membranes. At this stage, the samples begin to degrade at a temperature approximately $20^{\circ} \mathrm{C}$ lower than the membrane with 7.5 wt.\% Zr-MOF (SMOF7.5) and a larger mass loss of these membranes can be observed in 
this temperature range. This mass loss of the SPEEK/MOF-IL membranes may be related to the loss of the $\mathrm{HSO}_{4}{ }^{-}$anion of the ionic liquid. The third stage starts at approximately the same temperature for all samples, and it refers to the degradation of the main chain of the SPEEK membrane.

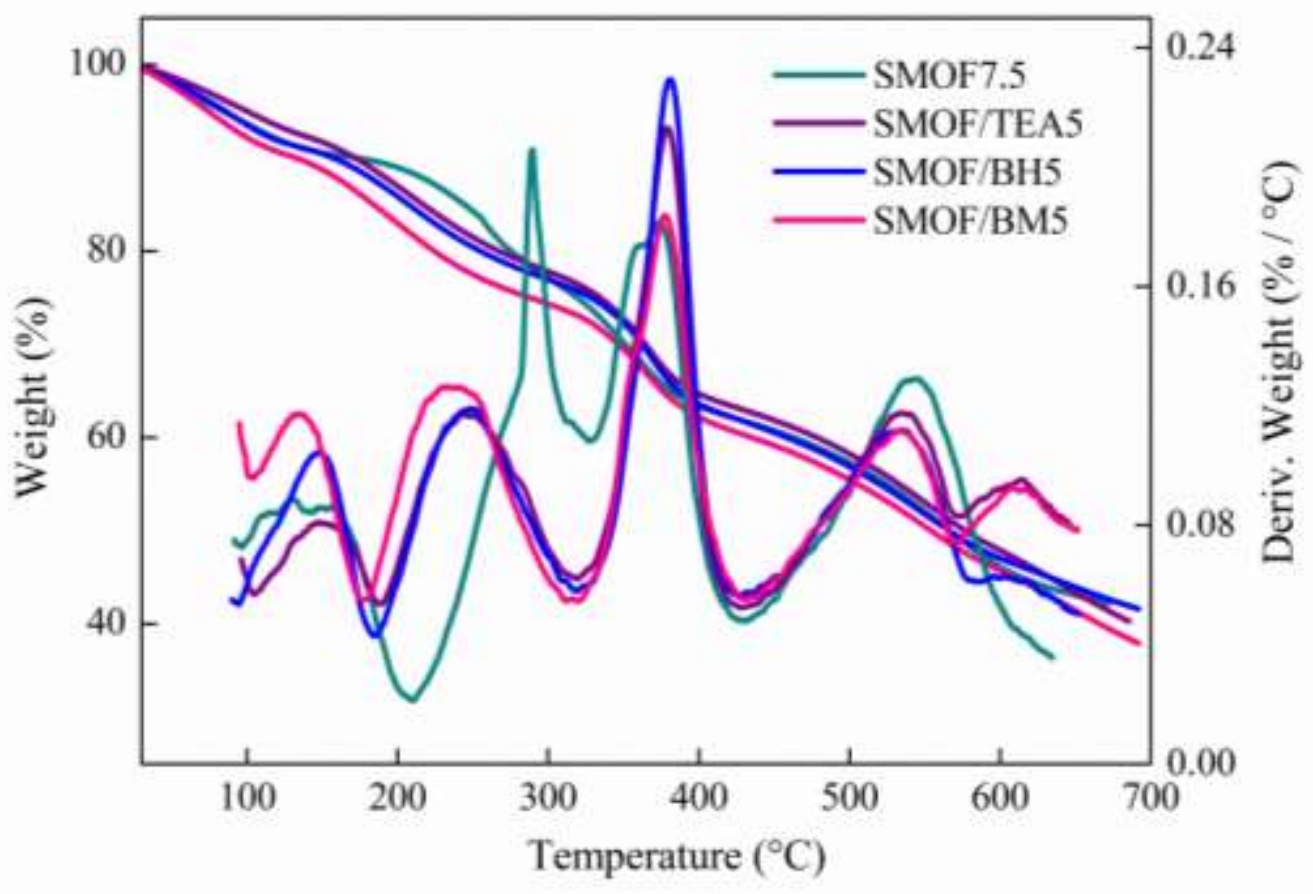

Figure S1. TG curves for SMOF7.5, SMOF/TP5, SMOF/BH5 and SMOF/BM5 samples. 

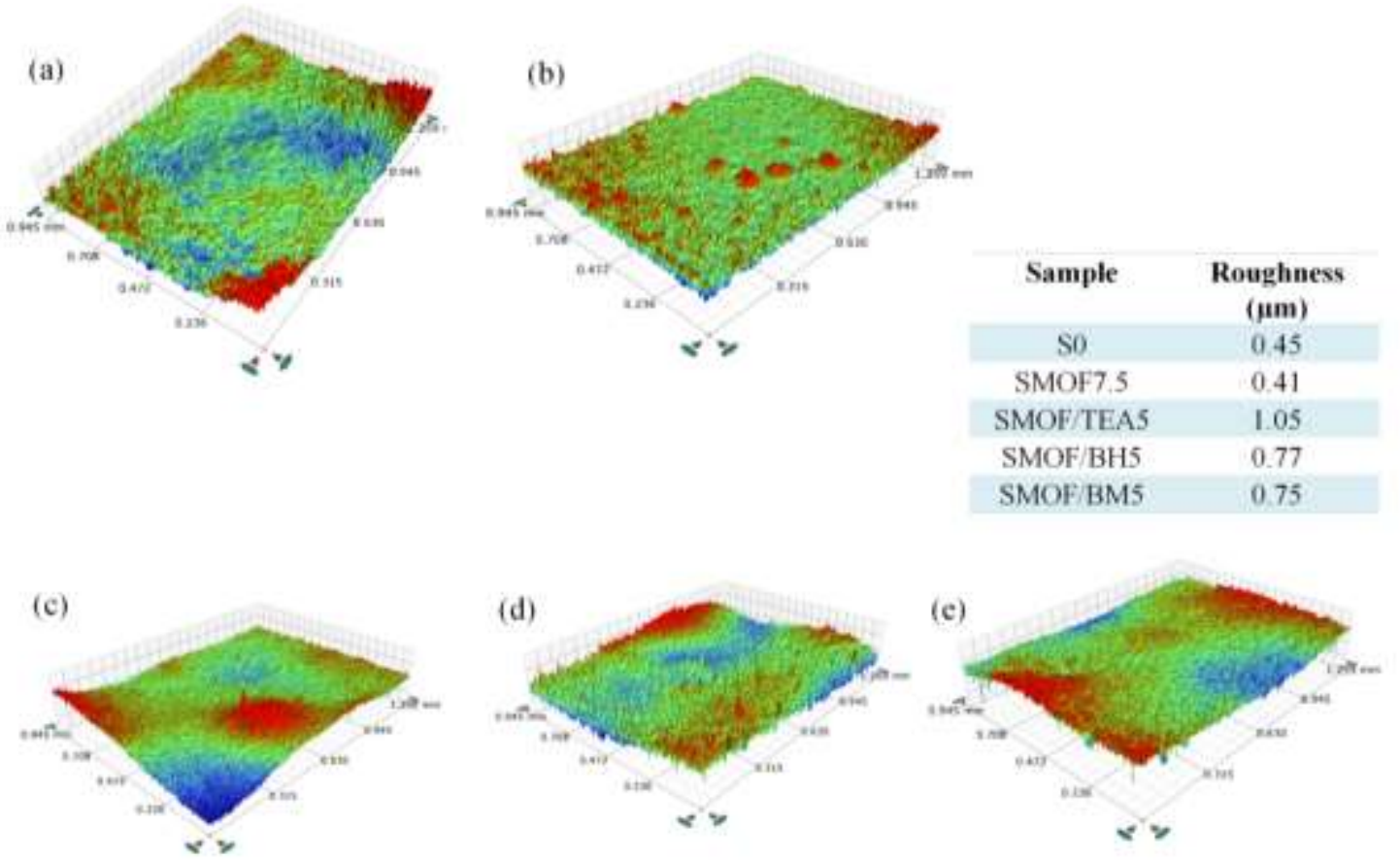

Figure S2. Profilometer images and roughness for (a) S0, (b) SMOF7.5, (c) SMOF/TP5, (d) SMOF/BH5 and (e) SMOF/BM5.

Figure S2 shows that the average surface roughness of the SPEEK membrane surface is practically unchanged with the addition of $7.5 \mathrm{wt} \% \mathrm{Zr}-\mathrm{MOF}$, with a small decrease of $0.04 \mu \mathrm{m}$ in the roughness value. For composite membranes SMOF/TP5, SMOF/BH5 and SMOF/BM5, the roughness values were $1.05 \mu \mathrm{m}, 0.77 \mu \mathrm{m}$ and $0.75 \mu \mathrm{m}$, respectively. The SMOF/TP5 membrane has a roughness of approximately 2.5 times greater than that of the SMOF7.5 sample, while SMOF/BH5 and SMOF/BM5 have a increase in roughness of approximately 1.8 times. This behavior may be associated with the cation size of the ionic liquids used. The size of the ionic liquid cations $(0.86,0.90$ and $0.98 \mathrm{~nm}$ for $\mathrm{BImH}^{+}, \mathrm{BMI}^{+}$and TEA-PS ${ }^{+}$, respectively) indicates that only part of the cation is inserted into the $\mathrm{Zr}-\mathrm{MOF}$ pore [41], because the $\mathrm{Zr}-\mathrm{MOF}$ has a triangular opening of $0.6 \mathrm{~nm}$, making it difficult for large molecules to enter [42]. As the TEA-PS ${ }^{+}$ cation has greater volume, it may not have completely entered the pore, being mostly 
around it, while the smaller $\mathrm{BmH}^{+}$and $\mathrm{BMI}^{+}$cations are able to accommodate better within the pores.

The cross-sectional images of pure SPEEK (S0) and SPEEK doped with MOF/IL particles are shown in Figure 8. It can be seen that the membranes were homogenously prepared, with no evident agglomerations in the SPEEK polymer matrix by MOF/IL particles.
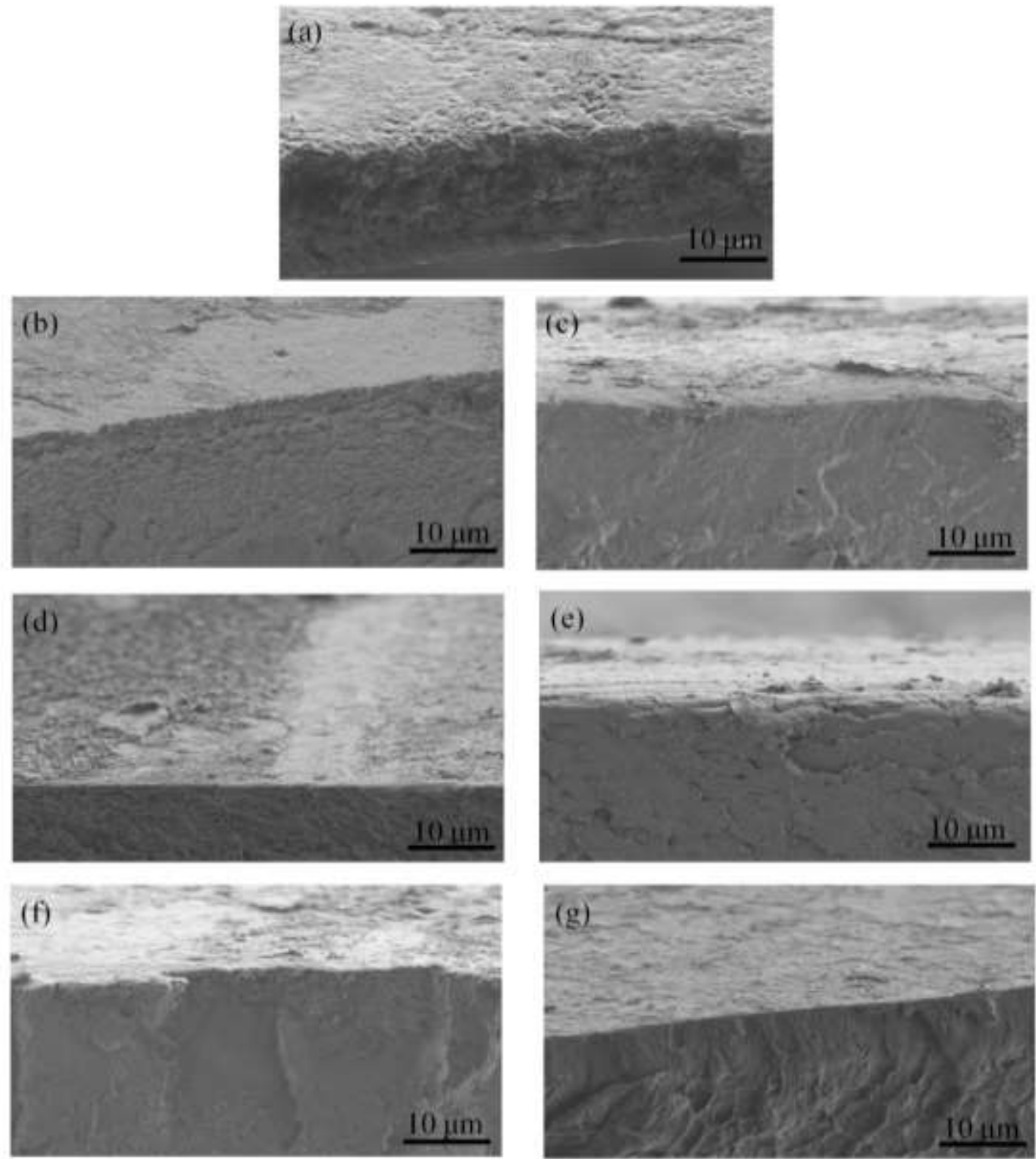

Figure 8. Cross-sectional images of $\mathrm{S} 0$ (a), SMOF/BH2.5 (b), SMOF/BH5 (c), SMOF/BM2.5 (d), SMOF/BM5 (e), SMOF/TEA2.5 (f) and SMOF/BTEA5 (g). 
In order to investigate whether the addition of the Zr-MOF/IL particles changes the wettability of the SPEEK membrane, the surface of the membranes was analyzed by contact angle measurements, shown in Figure 9 (a). In addition, in order to assess whether the change in the surface of the sample also influenced its water retention capacity, swelling tests were performed, and the results are shown in Figure 9 (b).
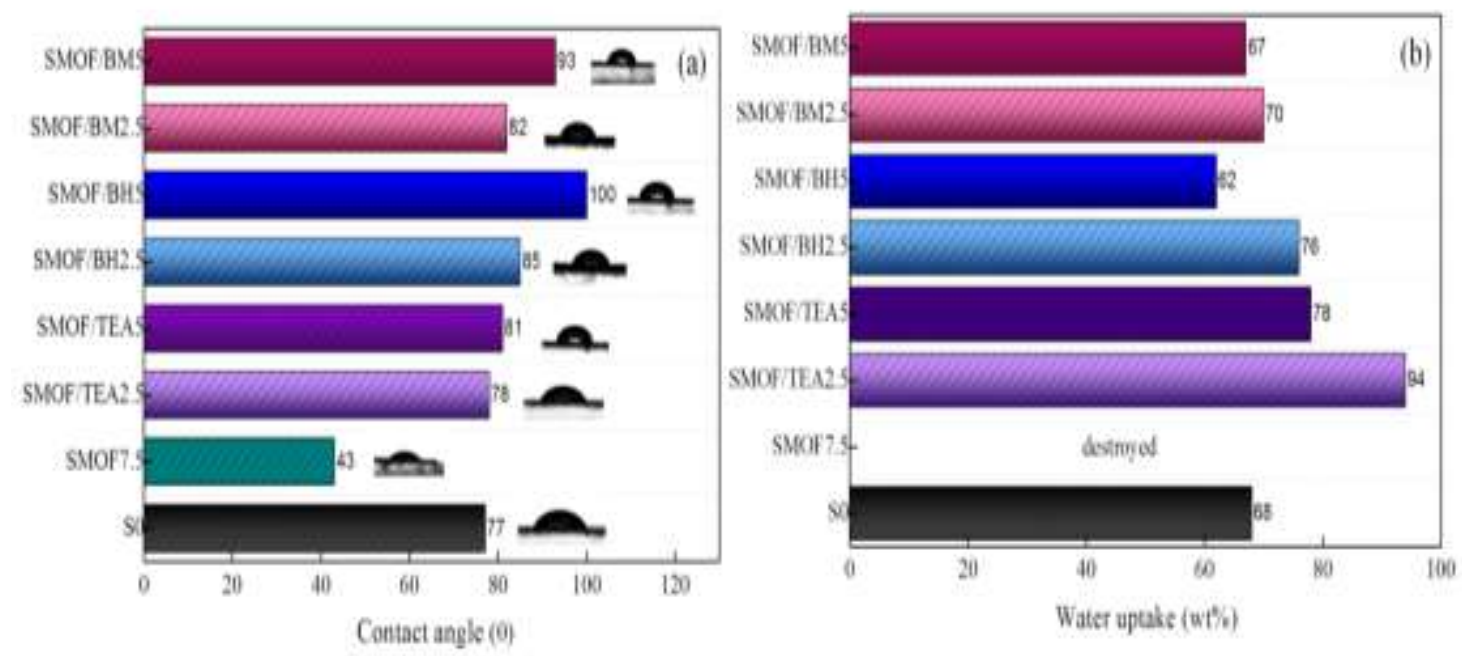

Figure 9. Contact angle (a) and water uptake (b) for S0, SMOF7.5, SMOF/TEA2.5, SMOF7/TEA5, SMOF/BH2.5, SMOF/BH5, SMOF/BM2.5 and SMOF/BM5.

It can be noted that, as the amount of IL increases from 2.5 to $5 \mathrm{wt} . \%$, the surface of the membranes become less hydrophilic and consequently have a reduced water uptake capacity. The contact angle increases from $85^{\circ}$ to $93^{\circ}$ and the water absorption is reduced from 70 to $67 \%$ for SMOF/BM2.5 and SMOF/BM5 composite membranes. For SMOF/BH2.5 and SMOF/BH5 samples, the values of contact angle were $82^{\circ}$ and $100^{\circ}$, which led to a reduction in water retention from $76 \%$ to $62 \%$. On the other hand, for the composite membranes with TEA-PS.HSO 4 ionic liquid (SMOF/TP2.5 and SMOF/TP5) the contact angle had a small variation, from $78^{\circ}$ to $81^{\circ}$ and the water absorption was reduced from $94 \%$ to $78 \%$, with increasing IL concentration. These results indicate that 
the three ionic liquids studied are in the pores of the $\mathrm{Zr}-\mathrm{MOF}$, improving the stability of the membrane and thus preventing its excessive swelling [43].

The SPEEK membrane with 7.5 wt.\% of Zr-MOF (SMOF7.5) presents a contact angle of $43^{\circ}$, indicating its high hydrophilicity, proven by its dissolution in water at 80 ${ }^{\circ} \mathrm{C}$. The fact that this membrane has high water retention may be related to $\mathrm{Zr}-\mathrm{MOF}$ structural factors, including pore size [44]. These factors facilitate the aggregation of water molecules within the pore, which are fixed by the formation of hydrogen bonds between the neighboring water molecules with the 1,4-benzoldicarboxylic acid binder [45].

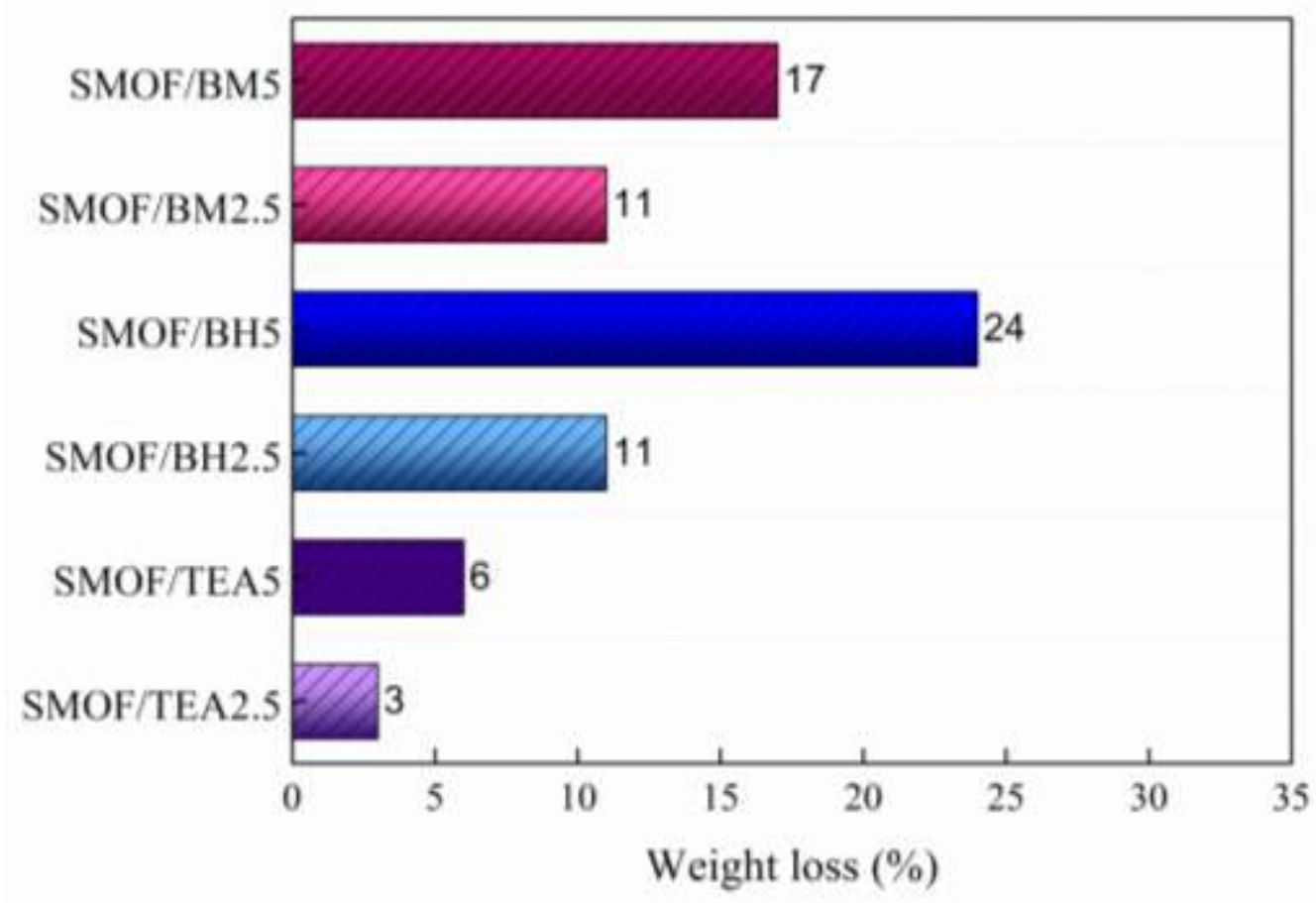

Figure S3. Leaching out of SMOF/TP2.5, SMOF/TP5, SMOF/BH2.5, SMOF/BH5, SMOF/BM2.5 and SMOF/BM5.

Figure S3 shows the ability of the ionic liquid to exit the membrane in aqueous medium. The samples show the same leaching tendency, that is, with an increase in the 
amount of IL encapsulated in the $\mathrm{Zr}-\mathrm{MOF}$, the leaching is increased. We can relate the pattern of leaching of the composite membranes with the interaction force of IL cations with the sulfonic group of SPEEK. The increase in leaching follows the order $\mathrm{BIm}^{+}$ $>\mathrm{BMI}^{+}>\mathrm{TEA}^{\mathrm{PS}}{ }^{+}$, indicating that the higher the cation, the greater the interaction of IL with $\mathrm{Zr}-\mathrm{MOF}$ and SPEEK.

The oxidative stability test, shown in Figure 10, was performed to evaluate whether the pure $\mathrm{Zr}-\mathrm{MOF}$ or the MOF/IL particles accelerate the chemical degradation of the SPEEK membrane. During PEMFC operation, reactive oxygen radicals $(\bullet \mathrm{OH}$, - $\mathrm{OOH})$ can be generated by a chemical or electrochemical reaction between hydrogen and oxygen in the Pt catalyst [46].

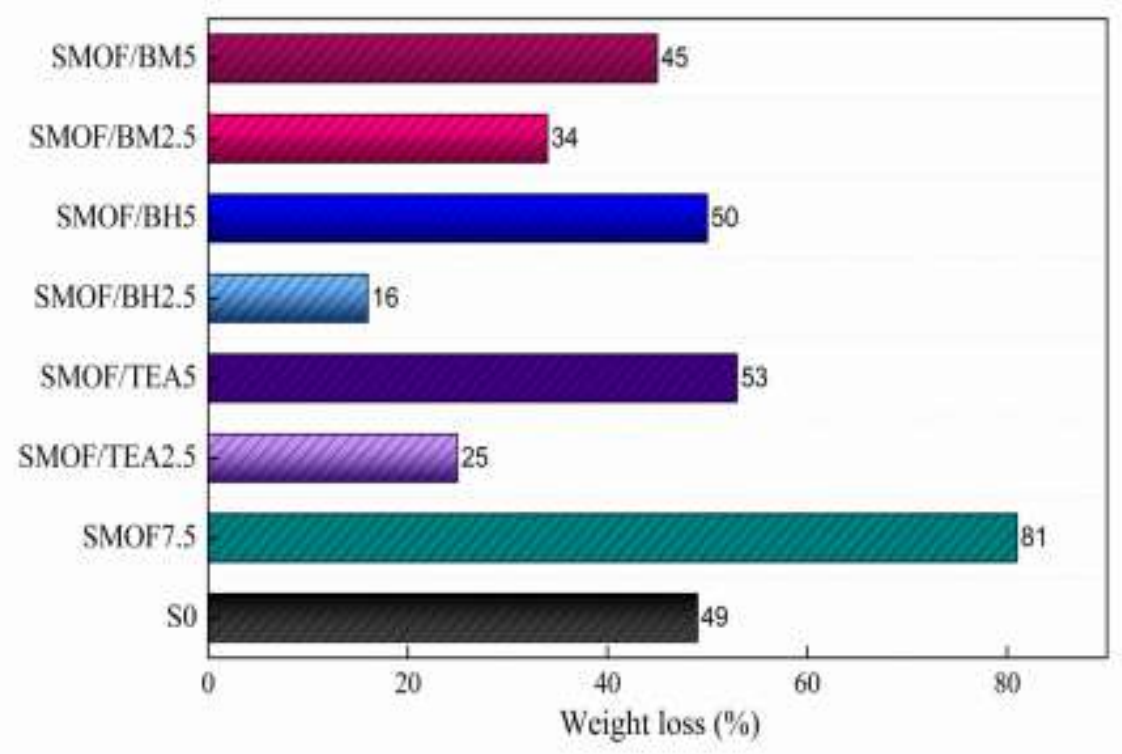

Figure 10. Oxidative stability for S0, SMOF7.5, SMOF/TEA2.5, SMOF/TEA5, SMOF/BH2.5, SMOF/BH5, SMOF/BM2.5 and SMOF/BM5 samples.

The results show that the addition of 7.5 wt.\% Zr-MOF to SPEEK increases membrane degradation by $26 \%$. However, when IL is encapsulated in the $\mathrm{Zr}-\mathrm{MOF}$ particles, the tendency of chemical degradation of the polymer is reduced for all 
concentrations. Nevertheless, it is noted that an increase in the concentration of encapsulated IL also increases the tendency of membrane degradation. It is known that oxygen radicals react with weak terminal groups of the polymers [46]. In the case of SPEEK, the attack of the radical is possibly to the sulfonic group. Therefore, the addition of pure $\mathrm{Zr}-\mathrm{MOF}$ accelerates the degradation of the membrane, because this material must be connected to these terminal groups by the formation of hydrogen bonds, further weakening it. This can be confirmed by the contact angle and water retention measurements (Figure 9): the addition of pure $\mathrm{Zr}-\mathrm{MOF}$ increases the hydrophilicity tendency of the membrane and consequently its degree of swelling, making this composite membrane more fragile and consequently leading to its degradation. However, the encapsulation of IL in the $\mathrm{Zr}$-MOF confers additional protection to these terminal groups, thus reducing decomposition. This decomposition process can be accelerated or slowed down depending on the amount of encapsulated ionic liquid, as shown in the results.

In order to evaluate the effect that the encapsulation of the IL in the $\mathrm{Zr}-\mathrm{MOF}$ particles has on the proton conductivity of the composite membranes, conductivity measurements were performed at $25^{\circ} \mathrm{C} / 100 \% \mathrm{RH}$ and $80{ }^{\circ} \mathrm{C} / 60 \% \mathrm{RH}$ (Table 4).

Table 4. Proton conductivity $(\sigma)$ and relative humidity $(\mathrm{RH})$ of SPEEK/MOF composite membranes with different amounts of ionic liquid at $25^{\circ} \mathrm{C}$ and $80{ }^{\circ} \mathrm{C}$.
Sample
$\left.\sigma(\mathbf{m S ~ c m})^{-1}\right)$ 


\begin{tabular}{ccc}
\hline & $\mathbf{2 5}^{\mathbf{0}} \mathbf{C}(\mathbf{1 0 0 \%} \mathbf{R H})$ & $\mathbf{8 0}^{\mathbf{0}} \mathbf{C}(\mathbf{6 0 \%} \mathbf{R H})$ \\
\hline SMOF/BH2.5 & 88 & 109 \\
SMOF/BH5 & 32 & 54 \\
SMOF/BM2.5 & 64 & 83 \\
SMOF/BM5 & 26 & 43 \\
SMOF/TEA2.5 & 92 & 140 \\
SMOF/TEA5 & 43 & 65 \\
\hline
\end{tabular}

As listed in Table 4, the proton conductivity values of all composite membranes were smaller than that of the SMOF7.5 composite membrane (Table 3). This result can be related to the decrease in water uptake of the composite membrane when the ionic liquid was encapsulated in the Zr-MOF. The conductivity and the water uptake properties of the composite membranes follow the same order: SMOF7.5 > SMOF/TEA > $\mathrm{SMOF} / \mathrm{BH}>\mathrm{SMOF} / \mathrm{BM}$. The conductivity of the SMOF7.5 membrane is higher in both conditions studied, since the Zr-MOF can form hydrogen bonds between the neighboring water molecules with the 1,4-benzoldicarboxylic acid binder [45]. On the other hand, when the ionic liquid is encapsulated in the $\mathrm{Zr}-\mathrm{MOF}$ pore of the, it prevents the water from entering, preventing the formation of hydrogen bonds decreased thus the proton conductivity. The results show that the ideal amount of ionic liquid encapsulated for increasing the conductivity in both studied temperatures $\left(25\right.$ and $\left.80^{\circ} \mathrm{C}\right)$ is $2.5 \mathrm{wt} . \%$, for the three ionic liquids used. The increase in the amount of encapsulated IL to $5 \mathrm{wt} . \%$ significantly decreases all conductivity values. This reduction in proton conductivity may be related to the increase of particle agglomerations inside in the polymer channel, which can block the membrane channels preventing water retention. [47]. The SMOF/TEA2.5 composite membrane presented the highest conductivity values among membranes modified with MOF/IL particles. This behavior can be attributed to the fact that the TEAPS.HSO $\mathrm{IL}_{4}$ has a $\mathrm{SO}_{3} \mathrm{H}$ group in the cation and a $\mathrm{SO}_{4} \mathrm{H}$ group in the anion. These groups 
are protonic and their dissociation produce more $\mathrm{H}^{+}$, thus contributing to the increase of proton conductivity. The proton conductivity measured at $80{ }^{\circ} \mathrm{C}$ is approximately $111 \%$ greater than the pure SPEEK membrane $\left(126 \mathrm{mS} \mathrm{cm}^{-1}\right)$ at the same temperature; this demonstrates that SMOF/TEA2.5 may be a promising membrane for use in PEMFC-type fuel cells.

\section{Conclusions}

SPEEK membranes modified with Zr-MOF and with ionic liquid encapsulated in ZrMOF were manufactured by the casting method. SPEEK/MOF composite membranes with 7.5 wt. $\%$ of $\mathrm{Zr}$-MOF exhibit high conductivity, but dissolve in water at $80{ }^{\circ} \mathrm{C}$. This behavior is attributed to structural factors of the MOF. The pore sizes of the MOF facilitate the aggregation of water molecules, which are fixed within the pores by hydrogen bonds. This increases conductivity, but also the degree of swelling, which causes MOF dissolution when in prolonged contact with water. In order to increase thermal and chemical stability of the membrane, BImH.HSO $4, \mathrm{BMI} . H S O_{4}$ and TEAPS.HSO4 ILs were encapsulated at $2.5 \mathrm{wt} \%$ and $5 \mathrm{wt} \%$ by wet impregnation method. As result, higher contact angles and low water absorption are obtained. Among the three ionic liquids tested in the SPEEK/Zr-MOF membranes, the composite membrane with

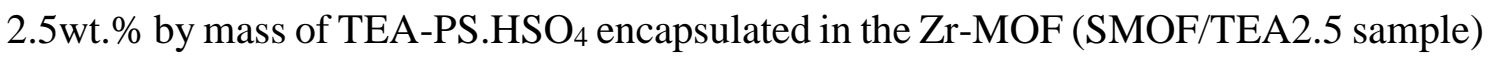
showed higher water retention capacity and the best proton conductivity result between the studied SPEEK/MOF-IL composite membranes. This high conductivity is attributed to the fact that the TEA-PS. $\mathrm{HSO}_{4} \mathrm{IL}$ has a $\mathrm{SO}_{3} \mathrm{H}$ group in the cation and a $\mathrm{SO}_{4} \mathrm{H}$ group in the anion. These groups are protonic and their dissociation produces more $\mathrm{H}^{+}$, thus contributing to the increase of proton conductivity. The results show that the SMOF/TEA2.5 membrane can be promising for PEMFC applications. 


\section{Acknowledgements}

The support of this research by CAPES, CNPq and FAPESP (2013/07296-2) is gratefully acknowledged. 


\section{References}

[1] H. Furukawa, O. M. Yaghi, Storage of hydrogen, methane, and carbon dioxide in highly porous covalent organic frameworks for clean energy applications, J. Am. Chem. Soc. 131 (2009) 8875-8883. http://dx.doi.org/10.1021/ja9015765

[2] E. Bakangura, L. Wu, L. Ge, Z. Yang, T. Xu, Mixed matrix proton exchange membranes for fuel cells: State of the art and perspectives, Prog. Polym. Sci. 57 (2016) 103-152. http://dx.doi.org/10.1016/j.progpolymsci.2015.11.004

[3] T. Luo, S. Abdu, M. Wesslinga, Selectivity of ion exchange membranes: A review, J. Membr. Sci. 555 (2018) 429-454. https://doi.org/10.1016/j.memsci.2018.03.051

[4] X. Cheng, J. Zhang, Y. Tang, C. Song, J. Shen, D. Song, J. Zhang, Hydrogen crossover in high-temperature PEM fuel cells, J. Power Sources 167 (2007) 25-31. http://dx.doi.org/10.1016/j.jpowsour.2007.02.027

[5] J. Jalili, S. Borsacchi, V. Tricoli, Proton conducting membranes in fully anhydrous conditions at elevated temperature: Effect of Nitrilotris(methylenephosphonic acid) incorporation into Nafion- and poly(styrenesulfonic acid), J. Membr. Sci. 469 (2014) 162173. https://doi.org/10.1016/j.memsci.2014.05.031

[6] Y. Shao, G. Yin, Z. Wang, Y. Gao, Proton exchange membrane fuel cell from low temperature to high temperature: Material challenges, J. Power Sources 167 (2007) 235242. http://dx.doi.org/10.1016/j.jpowsour.2007.02.065 
[7] A.L. Khan, C. Klaysom, A. Gahlaut, X. Li, I.F.J. Vankelecom, SPEEK and functionalized mesoporous MCM-41 mixed matrix membranes for $\mathrm{CO}_{2}$ separations, $\mathrm{J}$. Mater. Chem. 22 (2012) 20057-20064. http://dx.doi.org/10.1039/c2jm34885c

[8] H. Liu, H. Yu, Ionic liquids for electrochemical energy storage devices applications, J. Mat. Sci. Technol. 2018 In Press, Accepted Manuscript. https://doi.org/10.1016/j.jmst.2018.10.007

[9] R. Sood, C. Iojoiu, E. Espuche, F. Gouanvé, H. Mendil-Jakani, S. Lyonnard. Influence of different perfluorinated anion based Ionic liquids on the intrinsic properties of Nafion, J. Membr. Sci. 495 (2015) 445-456. https://doi.org/10.1016/j.memsci.2015.07.006

[10] X. Wang, M. Jin, Y. Li, L. Zhao. The influence of various ionic liquids on the properties of SPEEK membrane doped with mesoporous silica. Electrochim. Acta 257 (2017) 290-300. http://dx.doi.org/10.1016/j.electacta.2017.10.098

[11] Q. Xin, T. Liu, Z. Li, S. Wang, Y. Li, Z. Li, J. Ouyang, Z. Jiang, H. Wu. Mixed matrix membranes composed of sulfonated poly(etheretherketone) and a sulfonated metal-organic framework for gas separation, J. Membr. Sci. 488 (2015) 67-78. http://dx.doi.org/10.1016/j.memsci.2015.03.060

[12] U. Mueller, M. Schubert, F. Teich, H. Puetter, K. Schierle-Arndta, J. Pastréa. Metalorganic frameworks — prospective industrial applications. J. Mater. Chem. 16 (2006) 626636. http://dx.doi.org/10.1039/B511962F 
[13] B. Zhangab, Y. Cao, Z. Li, H. Wu, Y. Yin, L. Cao, X. He, Z, Jiang, Proton exchange nanohybrid membranes with high phosphotungstic acid loading within metal-organic frameworks for PEMFC applications, Electrochim. Acta 240 (2017) 186-194. http://dx.doi.org/10.1016/j.electacta.2017.04.087

[14] Z. Li, G. He, Y. Zhao, Y. Cao, H. Wu, Y. Li, Z. Jiang, Enhanced proton conductivity of proton exchange membranes by incorporating sulfonated metal-organic frameworks, J. Membr. Sci. 262 (2014) 372-379. http://dx.doi.org/10.1016/j.jpowsour.2014.03.123

[15] F. Fiegenbaum, M.O. de Souza, M.R. Becker, E.M.A. Martini, R.F.de Souza, Electrocatalytic activities of cathode electrodes for water electrolysis using tetra-alkylammonium-sulfonic acid ionic liquid as electrolyte, J. Power Sources 280 (2015) 12-17. https://doi.org/10.1016/j.jpowsour.2015.01.082.

[16] L. Zanchet, L.G. da Trindade, D.W. Lima; W. Bariviera, F. Trombetta, M.O. de Souza, E.M.A. Martini, Cation influence of new imidazolium-based ionic liquids on hydrogen production from water electrolysis, Ionics (2018). https://doi.org/10.1007/s11581-018-2803-0.

[17] K. Niknam, M. Damya, 1-Butyl-3-methylimidazolium hydrogen sulfate [bmim]HSO4: An efficient reusable acidic ionic liquid for the synthesis of 1,8-dioxooctahydroxanthenes. J. Chin. Chem. Soc. $56 \quad$ (2009) 659-665. https://onlinelibrary.wiley.com/doi/epdf/10.1002/jccs.200900098 
[18] J. Fraga-Dubreuil, K. Bourahla, M. Rahmouni, J.P. Bazureau, J. Hamelin, Catalysed esterifications in room temperature ionic liquids with acidic counteranion as recyclable reaction media, Catal. Commun. 3 (2002) 185-190. https://doi.org/10.1016/S15667367(02)00087-0

[19] S.J. Garibay, S.M. Cohen, Isoreticular synthesis and modification of frameworks with the UiO-66 topology. Chem. Commun. $46 \quad$ (2010) 7700-7702. https://doi.org/10.1039/c0cc02990d.

[20] J.B. De Coste, T.J. Demasky, M.J. Katz, O.K. Farha, J.T. Hupp, A UiO-66 analogue with uncoordinated carboxylic acids for the broad-spectrum removal of toxic chemicals, New J. Chem. 39 (2015) 2396-2399. https://doi.org/ 10.1039/c4nj02093f.

[21] F.P. Kinik, A. Uzun, S. Keskin, Ionic liquid/metal-organic framework composites: from synthesis to applications. Chem. Sus. Chem. 10 (2017) 2842-2863. https://doi.org/10.1002/cssc.201700716.

[22] L.G. da Trindade, E.C. Pereira, New anhydrous polymer membranes of SPEEK/zeolite/ionic liquid for fuel cell application, Eur. J. Inorg. Chem. 2017 (2017) 2369-2376. https://doi.org/10.1002/ejic.201601559.

[23]Y. Liang, C. Gong, Z. Qi, H. Li, Z. Wu, Y. Zhang, S. Zhang, Y. Li, Intermolecular ionic cross-linked sulfonated poly(ether ether ketone) membranes containing diazafluorene for direct methanol fuel cell applications, J. Power Sources 284 (2015) 8694. https://doi.org/10.1016/j.jpowsour.2015.02.159 
[24] A. Gutiérrez-Pardo, J. Ramírez-Rico, R. Cabezas-Rodríguez, J. Martínez-Fernández, Effect of catalytic graphitization on the electrochemical behavior of wood derived carbons for use in supercapacitors, J. Power Sources 278 (2015) 18-26. https://doi.org/10.1016/j.jpowsour.2014.12.030

[25] S. Park, H. Kim, Preparation of a sulfonated poly(ether ether ketone)-based composite membrane with phenyl isocyanate treated sulfonated graphene oxide for a vanadium redox flow battery, J. Electrochem. Soc. 163 (2016) A2293-A2298. https://doi.org/10.1149/2.0731610jes.

[26] J. Ding, Z. Yang, C. He, X. Tong, Y. Li, X. Niu, H. Zhang, UiO-66(Zr) coupled with $\mathrm{Bi}_{2} \mathrm{MoO}_{6}$ as photocatalyst for visible-light promoted dye degradation, J. Colloid Interface Sci. 497 (2017) 126-133. https://doi.org/10.1016/j.jcis.2017.02.060.

[27] Y. Luan, Y. Qi, Z. Jin, X. Peng, H. Gao, G. Wang. Synthesis of a flower-like Zr-based metal-organic framework and study of its catalytic performance in the Mannich reaction, RSC Advances 5 (2015) 19273-19278. https://doi.org/10.1039/C4RA15257C

[28] S. Rowshanzamir, S.J. Peighambardoust, M.J. Parnian, G.R. Amirkhanlou, A. Rahnavard, Effect of Pt-Cs2.5H0.5PW12O40 catalyst addition on durability of selfhumidifying nanocomposite membranes based on sulfonated poly (ether ether ketone) for proton exchange membrane fuel cell applications, Int. J. Hydrogen Energy 40 (2015) 549560, https://doi.org/10.1016/j.ijhydene.2014.10.134 
[29] J. Li, G. Xu, X. Luo, J. Xiong, Z. Liu, W. Cai, Effect of nano-size of functionalized silica on overall performance of swellingfilling modified Nafion membrane for direct methanol fuel cell application, Appl Energy 213 (2018) 408-414.

[30] M.B. Bajestani, S.A. Mousavi, Effect of casting solvent on the characteristics of Nafion/ $\mathrm{TiO}_{2}$ nanocomposite membranes for microbial fuel cell application, Int. J. Hydrogen Energy 41 (2016) 476 -482. https://doi.org/10.1016/j.ijhydene.2015.11.036

[31] L. Valenzano, B. Civalleri, S. Chavan; S. Bordiga, M.H. Nilsen, S. Jakobsen, K.P. Lillerud; C. Lamberti, Disclosing the complex structure of UiO-66 metal organic framework: A synergic combination of experiment and theory, Chem. Mater. 23 (2011) 1700-1718. https://doi.org/10.1021/cm1022882

[32] J. Xi, Z. Lia, L. Yu, B. Yin, L. Wang, L. Liu, X. Qiu, L. Chen, Effect of degree of sulfonation and casting solvent on sulfonated poly(ether ether ketone) membrane for vanadium redox flow battery, J. Power Sources 285 (2015) 195-204. https://doi.org/10.1016/j.jpowsour.2015.03.104

[33] A.G. Al Lafi, The sulfonation of poly(ether ether ketone) as investigated by twodimensional FTIR correlation spectroscopy. J. Appl. Polym. Sci. 132 (2015) 41242. https://doi.org/10.1002/app.41242

[34] Y. Han, M. Liu, K. Li, Y. Zuo, Y. Wei, S. Xu, G. Zhang, C. Song, Z. Zhang, X. Guo, Facile synthesis of morphology and size-controlled zirconium metal-organic framework 
UiO-66: the role of hydrofluoric acid in crystallization, Cryst. Eng. Comm. (2015) 64346440. https://doi.org/10.1039/C5CE00729A.

[35] S. Liu, C. Xie, S. Yu, F. Liu, Dimerization of rosin using Brønsted-Lewis acidic ionic liquid as catalyst, Catal. Commun. 9 (2008) 2030-2034. https://doi.org/10.1016/j.catcom.2008.03.045

[36] W. Zhang, K. Xu, Q. Zhang, D. Liu, S. Wu, F. Verpoort, X.M. Song, Oxidative desulfurization of dibenzothiophene catalyzed by ionic liquid [BMIm] $\mathrm{HSO}_{4}$. Ind. Eng. Chem. Res. (2010) 11760-11763. https://doi.org/10.1021/ie100957k.

[37] A.F. Ferreira, P.N. Simões, A.G.M. Ferreira, Quaternary phosphonium-based ionic liquids: Thermal stability and heat capacity of the liquid phase. J Chem Thermodyn. 45 (2012) 16-27. https://doi.org/10.1016/j.jct.2011.08.019

[38] D. Shang, X. Zhang, S. Zeng, K. Jiang, H. Gao, H. Dong, Q. Yang, S. Zhang, Protic ionic liquid $[\mathrm{Bim}]\left[\mathrm{NTf}_{2}\right]$ with strong hydrogen bond donating ability for highly efficient $\begin{array}{llllll}\text { ammonia } & \text { absorption. } & \text { Green } & \text { Chem. } & 19 & \text { (2017) }\end{array}$ https://doi.org/10.1039/c6gc03026b

[39] B.D. Cullity, S.R. Stock, Elements of X-ray diffraction, Third ed., Prentice Hall, Upper Saddler River, 2001.

[40] F. Ragon, P. Horcajada, H. Chevreau, Y.K. Hwang, U.H. Lee, S.R. Miller. In situ energy-dispersive $\mathrm{x}$-ray diffraction for the synthesis optimization and scale-up of the 
porous zirconium terephthalate UiO-66, Inorg. Chem. 53 (2014) 2491-500. https://doi.org/10.1021/ic402514n.

[41] J.F. Olorunyomi, K.-Y. Chan, L. Gao, A.A. Voskanyan, C.-Y.V. Li, Direct synthesis of anion exchange polymer threaded in a metalorganic framework through in situ polymerization of an ionic liquid, Microporous Mesoporous Mater. 259 (2018) 255-263. https://doi.org/10.1016/j.micromeso.2017.08.054

[42] J.H. Cavka, S. Jakobsen, U. Olsbye, N. Guillou, C. Lamberti, S. Bordiga, K.P. Lillerud, A new zirconium inorganic building brick forming metal organic frameworks with exceptional stability, J. Am. Chem. Soc. 130 (2008) 13850-13851. https://doi.org/10.1021/ja8057953

[43] L. Ahmadian-Alam, H. Mahdavi, A novel polysulfone-based ternary nanocomposite membrane consisting of metal-organic framework and silica nanoparticles: As proton exchange membrane for polymer electrolyte fuel cells, Renew. Energ. 126 (2018) 630639. https://doi.org/10.1016/j.renene.2018.03.075.

[44] A.B. Yaroslavtsev, Y.P. Yampolskii, Hybrid membranes containg inorganic nanoparticles, $\quad$ Mendeleev $\quad$ Commun. $24 \quad$ (2014) 319-326. https://doi.org/10.1016/j.mencom.2014.11.001.

[45] H. Furukawa, F. Gándara, Y.-B. Zhang, J. Jiang, W.L. Queen, M.R. Hudson, O.M. Yaghi, Water adsorption in porous metal-organic frameworks and related materials, J. Am. Chem. Soc. 136 (2014) 4369-4381. https://doi.org/10.1021/ja500330a 
[46] V.O. Mittal, H.R. Kunz, J.M. Fenton, $\mathrm{Is}_{2} \mathrm{H}_{2}$ involved in the membrane degradation mechanism in PEMFC, Electrochem Solid-State Lett, 9 (2006) A299-A302. https://doi.org/10.1149/1.2192696.

[47] J.H. Chun, S.G. Kim, J.Y. Lee, D.H. Hyeon, B-H Chun, S.H. Kim, K.T. Park, Crosslinked sulfonated poly(arylene ether sulfone)/silica hybrid membranes for high temperature proton exchange membrane fuel cells, Renew. Energ. 51 (2013) 22-28. https://doi.org/10.1016/j.renene.2012.09.005. 